\title{
In Vitro Analog of Operant Conditioning in Aplysia. I. Contingent Reinforcement Modifies the Functional Dynamics of an Identified Neuron
}

\author{
Romuald Nargeot, Douglas A. Baxter, and John H. Byrne \\ Department of Neurobiology and Anatomy and W. M. Keck Center for the Neurobiology of Learning and Memory, \\ The University of Texas-Houston Medical School, Houston, Texas 77030
}

Previously, an analog of operant conditioning in Aplysia was developed using the rhythmic motor activity in the isolated buccal ganglia. This analog expressed a key feature of operant conditioning, namely a selective enhancement in the occurrence of a designated motor pattern by contingent reinforcement. Different motor patterns generated by the buccal central pattern generator were induced by monotonic stimulation of a peripheral nerve (i.e., n.2,3). Phasic stimulation of the esophageal nerve (E n.) was used as an analog of reinforcement. The present study investigated the neuronal mechanisms associated with the genesis of different motor patterns and their modifications by contingent reinforcement. The genesis of different motor patterns was related to changes in the functional states of the pre-motor neuron B51. During rhythmic activity, B51 dynamically switched between inactive and active states. Bursting activity in B51 was associated with, and predicted, characteristic features of a specific motor pattern (i.e., pattern I). Contingent reinforcement of pattern I modified the dynamical properties of B51 by decreasing its resting conductance and threshold for eliciting plateau potentials and thus increased the occurrences of pattern I-related activity in B51. These modifications were not observed in preparations that received either noncontingent reinforcement (i.e., yoke control) or no reinforcement (i.e., control). These results suggest that a contingent reinforcement paradigm can regulate the dynamics of neuronal activity that is centrally programmed by the intrinsic cellular properties of neurons.

Key words: learning and memory; operant conditioning; contingent reinforcement; regenerative properties; neuronal dynamics; central pattern generator; buccal ganglia; Aplysia californica; B51
Operant conditioning is a form of associative learning in which the probability of occurrence of an emitted behavior (i.e., an operant) is modified by the delivery of reinforcement that is contingent on the occurrence of the behavior (Skinner, 1938; Konorski, 1948; Skinner, 1966; Maier, 1989). Different behaviors are possible in a given sensory context. In operant conditioning, the contingent association of reinforcement with a specific behavior selectively modifies the likelihood of occurrence of that behavior (Thorndike, 1911, 1933; Skinner, 1981).

Operant conditioning modifies the probabilistic occurrence of behaviors in both vertebrates (Thorndike, 1911; Skinner, 1938; Miller, 1969; Byrne, 1987; Jaeger et al., 1987; Schulz, 1987; Wolpaw, 1987) and invertebrates (Horridge, 1962; Hoyle, 1980; Booker and Quinn, 1981; Hawkins et al., 1985; Cook and Carew, 1986; Susswein et al., 1986; Lukowiak et al., 1996; Fitzgerald et al., 1997). Although various modifications in neuronal excitability, synaptic connections, and cell morphology have been associated with operant conditioning (Woollacott and Hoyle, 1977; Hoyle,

\footnotetext{
Received July 27, 1998; revised Dec. 1, 1998; accepted Dec. 30, 1998.

This research was supported by the Ernst Knobil Fellowship, Air Force Office of Scientific Research Grant F620-97-1-0049, Grant 011618-048 from the Texas Higher Education Coordinating Board, National Institute of Mental Health (NIMH) Grant R01 MH58321, and NIMH Award K05 MH00649. We thank F. D. Lorenzetti for rescoring the data using a blind procedure.

Correspondence should be addressed to Dr. John H. Byrne, Department of Neurobiology and Anatomy, The University of Texas Medical School at Houston, P.O. Box 20708, Houston, TX 77225.

Dr. Nargeot's present address: Université Bordeaux I, Laboratoire de Neurobiologie de Réseaux, Bât. Biologie Animale-B2, Avenue des Facultés, 33405 Talence, Cedex, France.

Copyright (ㄷ) 1999 Society for Neuroscience $\quad 0270-6474 / 99 / 192247-14 \$ 05.00 / 0$
}

1979, 1982; Jaffard et al., 1980; Jaffard and Jeantet, 1981; Skelton et al., 1987; Mahajan and Desiraju, 1988; Carp and Wolpaw, 1994; Feng-Chen and Wolpaw, 1996; Spencer et al., 1996; Wolpaw, 1997), little is known about the neuronal processes that govern the probabilistic genesis of behaviors and whether modification of these processes may underlie the selective effect of contingent reinforcement.

Central pattern generators (CPGs) are neuronal networks that participate in the genesis and switching between several different motor behaviors (McClellan, 1982; Mortin et al., 1985; Heinzel, 1988; Green and Soffe, 1996). Such emitted behaviors can be modified by operant conditioning (Cook and Carew, 1986; Susswein et al., 1986; Jaeger et al., 1987; Lukowiak et al., 1996). Thus, CPGs may be advantageous preparations for the study of neuronal processes underlying the probability with which operants are generated and how this process can be controlled and shaped by contingent reinforcement.

The buccal ganglia in Aplysia contain a neuronal network that generates different consummatory feeding behaviors (e.g., ingestion, egestion) (Kupfermann, 1974a). These behaviors can be modified by associative learning, including operant and classical conditioning (Susswein et al., 1986; Colwill et al., 1997; Lechner et al., 1997). Recently, a neuronal analog of operant conditioning in the isolated buccal ganglia was developed to provide a suitable preparation to mechanistically analyze this example of associative learning (Nargeot et al., 1997b). In the present study, we investigated the neuronal processes associated with the probabilistic occurrences of the different motor patterns and their modifications by contingent reinforcement in the isolated buccal ganglia of 
Aplysia. In our companion paper in this issue of the journal (Nargeot et al., 1999a), we investigated how the contingentdependent modifications of these neuronal processes contributed to the selection of a designated motor output.

Preliminary reports of these results have been published previously in abstract form (Nargeot et al., 1997a, 1998).

\section{MATERIALS AND METHODS}

The experimental procedures of the present study were similar to those described previously (Nargeot et al., 1997b). Animals were picked randomly from an aquarium. They were food-deprived for $2 \mathrm{~d}$ before the experiment and fed a piece of seaweed $45 \mathrm{~min}$ before the beginning of an experiment. Subsequently, animals were anesthetized by injection of an isotonic solution of $\mathrm{MgCl}_{2}(360 \mathrm{~mm})$. Buccal ganglia were isolated and pinned out in a Sylgard-coated Petri dish containing artificial seawater (ASW) composed of (in $\mathrm{mM}$ ): $\mathrm{NaCl} 450, \mathrm{KCl} 10, \mathrm{MgCl}_{2}\left(6 \mathrm{H}_{2} \mathrm{O}\right) 30$, $\mathrm{MgSO}_{4} 20, \mathrm{CaCl}_{2}\left(2 \mathrm{H}_{2} \mathrm{O}\right) 10$, Trizma $10 ; \mathrm{pH}$ was adjusted to 7.4 . The left ganglion was desheathed on the rostral side. Desheathing was performed in presence of high divalent cation ASW containing three times (i.e., 30 $\mathrm{mm}$ ) the normal concentration of $\mathrm{CaCl}_{2}$ and three times (i.e., $90 \mathrm{~mm}$ ) the normal concentration of $\mathrm{MgCl}_{2}$. Osmolarity was maintained by decreasing the $\mathrm{NaCl}$ concentration to $330 \mathrm{~mm}$. The buccal ganglia were washed with ASW immediately after desheathing. The solutions were maintained at $15^{\circ} \mathrm{C}$ in the dish by means of a Peltier cooling device and were static (i.e., not perfused) during the experiment.

Figure $1 A$ illustrates the positioning of extracellular and intracellular electrodes that were used to stimulate and record neuronal activity. Stimulating electrodes were positioned on the buccal nerve 2,3 (n.2,3) and the anterior branch of the esophageal nerve (E n.2) that were ipsilateral to the desheathed ganglia. Monotonic stimulation of n.2,3 was composed of brief $(0.5 \mathrm{msec})$ pulses delivered at $4 \mathrm{~Hz}, 8.5 \mathrm{~V}$ with a train duration as described in Results. Stimulation of E n. 2 consisted of brief $(0.5 \mathrm{msec})$ pulses delivered at $10 \mathrm{~Hz}, 8 \mathrm{~V}$ for $6 \mathrm{sec}$. After the electrodes were in place, their efficacy to elicit neural activity was tested. Experiments began after a $40 \mathrm{~min}$ rest period after these initial test stimuli.

Classification of different motor patterns. In vivo recordings from peripheral buccal nerves during consummatory feeding behaviors have demonstrated that the neuronal activity occurring during ingestion and egestion can be distinguished by the phase relationship of motor activity mediating the closure of the radula relative to the motor activities mediating protraction and retraction of the radula (Morton and Chiel, 1993a,b). This study indicated that ingestion was associated with buccal motor patterns in which at least $50 \%$ of the closure motor activity occurred during the retraction phase. Egestion was associated with buccal motor patterns in which the closure motor activity preceded the retraction phase (i.e., occurred during the protraction phase).

In the isolated buccal ganglia, a pattern of neuronal activity was defined by bursting activity recorded simultaneously in nerves to intrinsic muscle 2 (I2 n.) (see Fig. $1 A$ ), in the branch of the radular nerve innervating the intrinsic muscle 4 (R n.1) (see Fig. $1 A$ ), and in n.2,1 (see Fig. $1 A$ ). A pattern began with bursting activity in $\mathrm{I} 2$ n. [i.e., protraction phase of the pattern (Hurwitz et al., 1996)] and ended with the termination of bursting activity in n.2,1 [i.e., the retraction phase of the pattern (Nargeot et al., 1997b)]. The transition between protraction and retraction phases was defined by termination of activity in I $2 \mathrm{n}$. (Hurwitz and Susswein, 1996). Thus, the duration of the retraction phase was measured from the termination of bursting activity in $\mathrm{I} 2 \mathrm{n}$. to the termination of bursting activity in n.2,1 (see Fig. $3 A$ ).

The buccal motor patterns, which appear to be related to feeding behaviors, were classified into three categories (i.e., pattern I, pattern II, and intermediate patterns) according to the phase relationship of largeamplitude bursting activity in R n.1 [i.e., activity of the closure motor neurons B8 (Morton and Chiel, 1993b; Nargeot et al., 1997b)] relative to the protraction and retraction phases of the pattern. The methods used to classify patterns were identical to those described earlier in Nargeot et al. (1997b). In a pattern, the large-amplitude unit activity in R n.1 was defined by action potentials greater than or equal to a designated threshold. This threshold was set equal to the amplitude of the smallest spike in $\mathrm{R} n .1$ that occurred during the protraction phase of patterns and was above the baseline activity recorded before patterns. This threshold was established in each preparation in either the positive or negative polarity depending on which polarity had the largest amplitude. The phase relationship of the large-amplitude bursting activity in $\mathrm{R} \mathrm{n.1}$ was determined by comparing the duration of this activity during the protraction phase with the duration of this activity during the retraction phase of a pattern. Spikes occurring at a frequency $<0.25 \mathrm{~Hz}$ during either the protraction or retraction phases were not considered as part of a burst of activity and were not taken into account for the calculation of the duration of bursting activity. The large-amplitude unit activity of a frequency $\geq 0.25 \mathrm{~Hz}$ may occur as a single burst or a sequence of bursts. In cases where burst sequences were observed, the duration of this activity occurring during the protraction phase was calculated as the sum of the duration of each individual burst that occurred before the protraction/retraction phase transition. Similarly, the duration of the largeamplitude bursting activity in $\mathrm{R} \mathrm{n.1}$ occurring during the retraction phase was calculated as the sum of the duration of the individual bursts that occurred after the protraction/retraction phase transition.

In pattern I (i.e., ingestion-like pattern), the duration of the largeamplitude bursting activity in $\mathrm{R} n$. 1 during the retraction phase was equal to or greater than the duration of this activity in the protraction phase. Thus, in pattern I, at least $50 \%$ of the large-amplitude bursting activity in $\mathrm{R}$ n.1 was expressed after the protraction phase (i.e., during the retraction phase). In pattern II (i.e., egestion-like pattern), the large-amplitude bursting activity in $\mathrm{R} n .1$ occurred only during the protraction phase. In intermediate patterns, the duration of the large-amplitude bursting activity in $\mathrm{R} n .1$ that occurred during the retraction phase was shorter than the duration of this activity in the protraction phase. Thus, in intermediate patterns, $<50 \%$ of the closure motor activity occurred during the retraction phase.

To assess the reproducibility of classifying the different patterns, neuronal activity expressed during a $10 \mathrm{~min}$ period of all experiments reported in this and our companion paper (Nargeot et al., 1999a) were also scored by an independent observer (i.e., blind observer) who was not aware of the purpose of the experiment. The reproducibility of the observations was quantified by calculating the percentage differences between the initial classification by the authors and the classification by the blind observer and by determining the concordance correlation coefficient (Zar, 1996) between the two observers for each type of pattern. There was no more than a $4 \%$ difference between observers in the classification of pattern. Moreover, the concordance correlation coefficients were high for each pattern that was classified (pattern I, 0.99; pattern II, 0.96; intermediate pattern, 0.98 ; incomplete patterns, 0.98 ; see below). These results suggest that classification of patterns was sufficiently objective and that different observers could readily distinguish the different types of patterns.

We occasionally observed bursts of activity that occurred in only one or two of the nerves. Because these incomplete patterns have not been described in vivo, preparations $(11 \%)$ were discarded if $>33 \%$ of the observed patterns were incomplete. Moreover, preparations $(12 \%)$ were not used if the initial frequency of spontaneous rhythmic motor patterns was $>0.01 \mathrm{~Hz}$ (Nargeot et al., 1997b).

Cell identification. Neurons B8 and B51 were identified by their axonal projections in the radular nerve, the phase relationship of their activity during motor patterns, their membrane properties, and their relative position in a buccal ganglion as described by Plummer and Kirk (1990), Church et al. (1991), Church and Lloyd (1991, 1994), and Morton and Chiel (1993a).

Testing paradigm for membrane properties in B51. Two-electrode current-clamp techniques were used to measure membrane properties (i.e., burst threshold, input resistance) of B51. During the test procedure, the resting membrane potential of the cell was held at $-60 \mathrm{mV}$. Preparations $(16 \%)$ in which B51 fired continuously at this membrane potential were discarded. Membrane properties were tested before and after training with $5 \mathrm{sec}$ hyperpolarizing and depolarizing current pulses. The hyperpolarizing current pulses were always applied before the depolarizing current pulses. Although no peripheral nerve stimulation was used during these periods, some spontaneous synaptic inputs to B51 and spontaneous motor patterns could occur. Current pulses were not delivered in the presence of such spontaneous activity. Moreover, the responses to current pulses that occurred during the $10 \mathrm{sec}$ preceding a spontaneous motor pattern were not considered. Finally, current pulses were delivered after a minimum of $60 \mathrm{sec}$ after a spontaneous motor pattern, or after a burst of activity in B51 elicited by a previous test pulse. In all other cases, the interpulse interval was $10 \mathrm{sec}$. The input resistance of B51 was calculated using the difference between the resting potential immediately before a hyperpolarizing pulse and the potential during the final $1 \mathrm{sec}$ of the test pulse. Burst threshold in B51 was defined as the minimum amount of depolarizing current necessary to elicit activity in B51 that outlasted the current pulse in two successive pulses of same 
A.
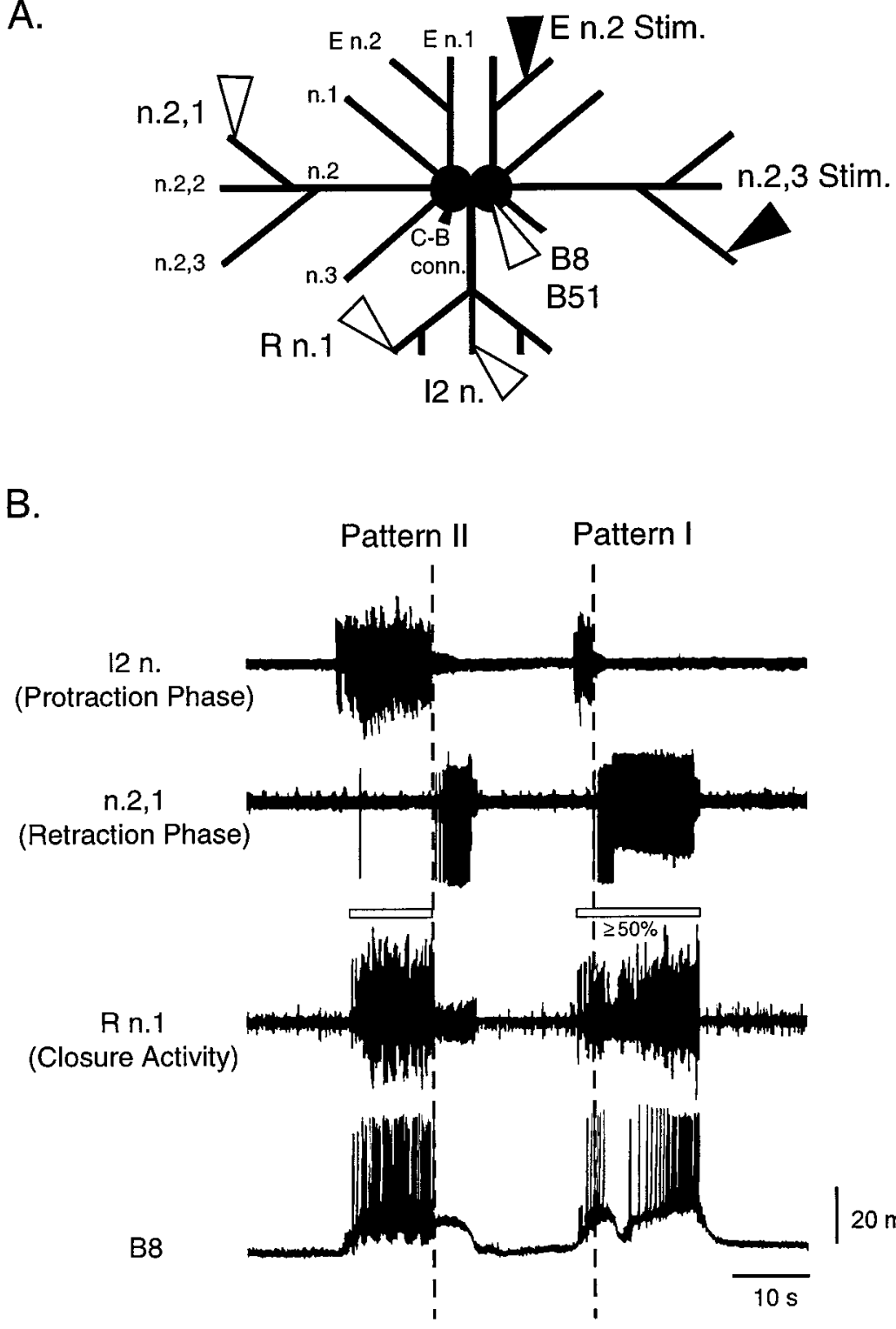

Figure 1. Switching between distinct buccal motor patterns. $A$, Schematic representation of the isolated buccal ganglia preparation used in the present study. The relative positions of the extracellular and intracellular recording electrodes (white triangles) and the stimulating electrodes (black triangles) are indicated. $B$, Monotonic $(4 \mathrm{~Hz})$ stimulation of n.2,3 induced rhythmic activity that randomly switched between different motor patterns (e.g., pattern I and pattern II). These patterns were basically composed of a protraction phase (i.e., activity in $\mathrm{I} 2 \mathrm{n}$.), a retraction phase (i.e., activity in n.2,1) (vertical dashed lines indicate transition between these two successive phases), and closure motor activity as monitored in a motor neuron B8 and the large-amplitude activity in R n.1 (horizontal bars). Different patterns were distinguished by the phase relationship of the closure activity and the duration of the retraction phase. In pattern II, the closure activity occurred during the protraction phase and preceded a short retraction phase. In pattern I, the closure activity occurred primarily (at least 50\%) during a prolonged retraction phase.

intensity. Preparations $(5 \%)$ in which electrodes were dislodged from B51 were discarded. Finally, experiments (4\%) were not included when no bursting activity could be elicited in B51 during the pretraining test.

Data analysis. Statistical comparisons between three paired samples were made using the Friedman test $\left(\chi^{2}\right)$. Comparisons between three unpaired samples were made using the Kruskal-Wallis test $(H)$. Critical values of the Kruskal-Wallis test were approximated by critical values of $\chi^{2}$ distribution (Zar, 1996). Post hoc pairwise multiple comparisons were made using the nonparametric Newman-Keuls multiple range test $(q)$. Correlation coefficients were tested by ANOVA $(F)$. Departures from normality of the data were tested using D'Agostino's test, and heterogeneity of variances of the data were tested using Bartlett's test (Zar, 1996). Probabilities (i.e., $p$ values) $<0.05$ were considered statistically significant.

\section{RESULTS}

\section{Dynamics of buccal motor output}

Consummatory feeding behaviors in Aplysia are rhythmic motor behaviors that include both ingestion (i.e., biting and swallowing) and egestion. Ingestion and egestion can be distinguished by the phase relationship of the movements of the odontophore (i.e., a tongue-like organ) and its grasping surface, the radula (Morton and Chiel, 1993a). The radula/odontophore rhythmically protract and retract. During ingestion, the radula is closed primarily during its retraction and thereby draws grasped objects into the buccal cavity. During egestion, the radula is closed only during its protraction and thus expels grasped objects from the buccal cavity. Consummatory feeding behaviors are composed of variable sequences of ingestion and egestion, which implies that the underlying neuronal circuitry switches from one output to another (Kupfermann, 1974b).

The buccal ganglia contain the CPG that mediates the movements of the radula/odontophore. In the isolated buccal ganglia, rhythmic motor activity composed of neuronal correlates of protraction, retraction, and closure of the radula/odontophore can be induced by monotonic (4 Hz) stimulation of n.2,3 (Fig. 1, n.2,3) (Nargeot et al., 1997b). These activities are organized into different motor patterns (i.e., pattern I, pattern II, and intermediate patterns), which can be distinguished on the basis of the phase relationship of closure motor activity (Fig. $1 B$ ) (see Materials and Methods). In addition to differences in phase relationship, we 
found that motor patterns could be characterized by the duration of their retraction phase. The duration of activity in n.2,1 (i.e., duration of the retraction phase; see Materials and Methods) differed significantly in the different motor patterns $\left(X^{2}=13.273\right.$; $\mathrm{df}=2 ; p<0.001$; data are from 11 preparations in which the mean duration of the retraction phase was calculated in each preparation from the successive patterns occurring during a $1 \mathrm{hr}$ period or until the 50th pattern). This duration was significantly longer in pattern I $(14.5 \pm 1.8 \mathrm{sec}$; mean \pm SEM $)$ than either intermediate patterns $\left(12.0 \pm 1.6 \mathrm{sec} ; q_{2}=4.264 ; p<0.005\right)$ or in pattern II $\left(7.8 \pm 1.4 \mathrm{sec} ; q_{3}=5.126 ; p<0.001\right)$ and was longer in intermediate patterns than in pattern II $\left(q_{2}=2.985 ; p<0.05\right)$. Thus, the phase relationship of closure motor activity as well as the duration of activity in n.2,1 varied among the different types of motor patterns (Fig. 1B).

During rhythmic activity induced by monotonic stimulation of n.2,3, the buccal CPG switched between expressing the different types of motor patterns (Fig. $1 B$ ). These switches occurred repetitively throughout the period of stimulation but had no apparent predictable pattern or frequency of occurrence. Thus, the expression of given motor patterns was probabilistic. Switching was rapid, so that motor patterns as different as pattern I and pattern II can occur in immediately adjacent cycles of the rhythmic activity (i.e., within $\sim 10 \mathrm{sec}$ ) (Fig. $1 B$ ). These dynamics of the CPG output indicated that monotonic stimulation of n.2,3 allowed a state that was permissive for probabilistic occurrences of different motor patterns that were similar to those recorded during consummatory feeding behaviors.

\section{Dynamics of activity in pre-motor neuron B51}

The timing and type of switching between different motor patterns induced by monotonic stimulation of n.2,3 were not determined by changes in the characteristics of the stimulation (e.g., timing, intensity, frequency). Rather, some neuronal processes that were intrinsic to the CPG appeared to underlie the probabilistic switching.

Neuron B51 participates in the buccal pattern generator, and a postsynaptic follower motor neuron (i.e., B15) has been described as being active only during ingestion (Cropper et al., 1990; Plummer and Kirk, 1990; Evans and Cropper, 1998). Thus, activity in B51 could participate in the genesis of pattern I (i.e., ingestionlike pattern) and may contribute to the probabilistic occurrence of pattern I and the switching between this and other patterns. To test this possibility, we investigated the relationship between activity in B51 and the dynamics of the buccal motor output.

In 11 preparations, we simultaneously recorded activity in a single B51 and the buccal motor patterns that were induced during a $1 \mathrm{hr}$ period of monotonic stimulation of n.2,3. Cell B51 did not fire action potentials during all motor patterns (Fig. $2 A$ ). Although B51 was depolarized in phase with the motor patterns, it failed to express action potentials during some patterns. This intermittent and unpredictable activity in B51 resulted from abrupt switches between inactive and active states rather than from a systematic buildup of the firing rate during successive patterns. These switches appeared to occur with no regular periods (see Fig. 5). However, when B51 did fire, its activity was in phase with the motor patterns. Thus, the dynamical activity of B51 was characterized by the selective recruitment of firing in B51 into the rhythmic motor patterns. We investigated whether such dynamical activity of B51 was associated with specific features of the motor output.

In the 11 preparations, the correlation between the different inactive and active states of B51 and the occurrences of different motor patterns was characterized. The occurrences of the inactive state of B51 were not uniformly distributed among the different motor patterns $\left(\chi^{2}=10.619\right.$; $\left.\mathrm{df}=2 ; p<0.005\right)$. Neuron B51 was inactive in $75.3 \pm 10.7 \%$ of pattern II, in $15.3 \pm 6.6 \%$ of pattern I, and in $27.0 \pm 9.3 \%$ of intermediate patterns. The proportion of patterns in which B51 was inactive was significantly higher in pattern II than either in pattern I $\left(q_{3}=4.221 ; p<0.01\right)$ or in intermediate patterns $\left(q_{2}=4.904 ; p<0.001\right)$. No significant difference was observed between the proportions of pattern I and intermediate patterns in which B51 was inactive $\left(q_{2}=1.066\right)$. Thus, the inactive state of B51 was significantly related to the occurrences of pattern II, and conversely, the active state of B51 was associated with the occurrences of both pattern I and intermediate patterns.

Activity in B51 can vary from a single action potential to a high-frequency burst of action potentials. We tested whether different levels of B51 activity were correlated with different motor patterns. The proportion of motor patterns in which B51 fired a burst of action potentials, defined as an activity higher than $4 \mathrm{~Hz}$ for $>1 \mathrm{sec}$, was significantly different among the different types of patterns $\left(\chi^{2}=19.581 ; \mathrm{df}=2 ; p<0.001\right)$. This proportion was significantly higher in pattern I $(76.7 \pm 7.0 \%)$ than either in pattern II $\left(6.7 \pm 3.7 \% ; q_{3}=6.181 ; p<0.001\right)$ or intermediate patterns $\left(48.0 \pm 9.0 \% ; q_{2}=4.051 ; p<0.005\right)$ (Fig. $\left.2 B\right)$. This proportion was also significantly different between intermediate patterns and pattern II $\left(q_{2}=4.690 ; p<0.001\right)$. Moreover, the percentage of patterns in which B51 was active for $1 \mathrm{sec}$ or less or with a frequency lower than $4 \mathrm{~Hz}$ was also heterogeneously distributed among the different types of motor patterns $\left(\chi^{2}=\right.$ $7.744 ; \mathrm{df}=2 ; p<0.021)$. This proportion was significantly higher in intermediate patterns $(25.0 \pm 9.1 \%)$ than either in pattern I $\left(8.0 \pm 2.9 \% ; q_{3}=3.467 ; p<0.05\right)$ or pattern II $\left(18.0 \pm 9.4 \% ; q_{2}\right.$ $=4.051 ; p<0.005)$. No significant difference was observed between these proportions in pattern I and pattern II $\left(q_{2}=\right.$ $0.853)$.

These results indicate that intense bursting activity in B51 (i.e., $>4 \mathrm{~Hz}$ for $>1 \mathrm{sec}$ ) was associated primarily with occurrences of pattern I. In contrast, weak activity in B51 (i.e., $<4 \mathrm{~Hz}$ or for no more than $1 \mathrm{sec}$ ) was related primarily to the occurrences of intermediate patterns. Finally, activity in B51 was not significantly represented in pattern II. Thus, the dynamics of activity in B51 appeared to reflect aspects of the dynamics of occurrences of the different motor patterns. We investigated the relationship between activity in B51 and the neural events that characterized these patterns (i.e., extension of the closure motor activity into the retraction phase and the duration of the retraction phase).

\section{Correlation between B51 activity and features of pattern I}

The activity in B51 always occurred during the retraction phase of motor patterns (Fig. $2 A$ ). Because B51 was active during pattern I and intermediate patterns, we examined the correlation between activity in B51 and two neuronal events that occur during the retraction phase of these patterns. These events were the duration of the closure motor activity (i.e., large-amplitude activity in $\mathrm{R}$ n.1) and the duration of the retraction phase (i.e., activity in n.2,1) (Fig. 3A).

The mean duration of activity in B51, of the large-amplitude activity in $\mathrm{R}$ n.1 occurring during the retraction phase, and of activity in n.2,1 were calculated from all pattern I and intermediate patterns expressed in each of the 11 preparations. These 
A.

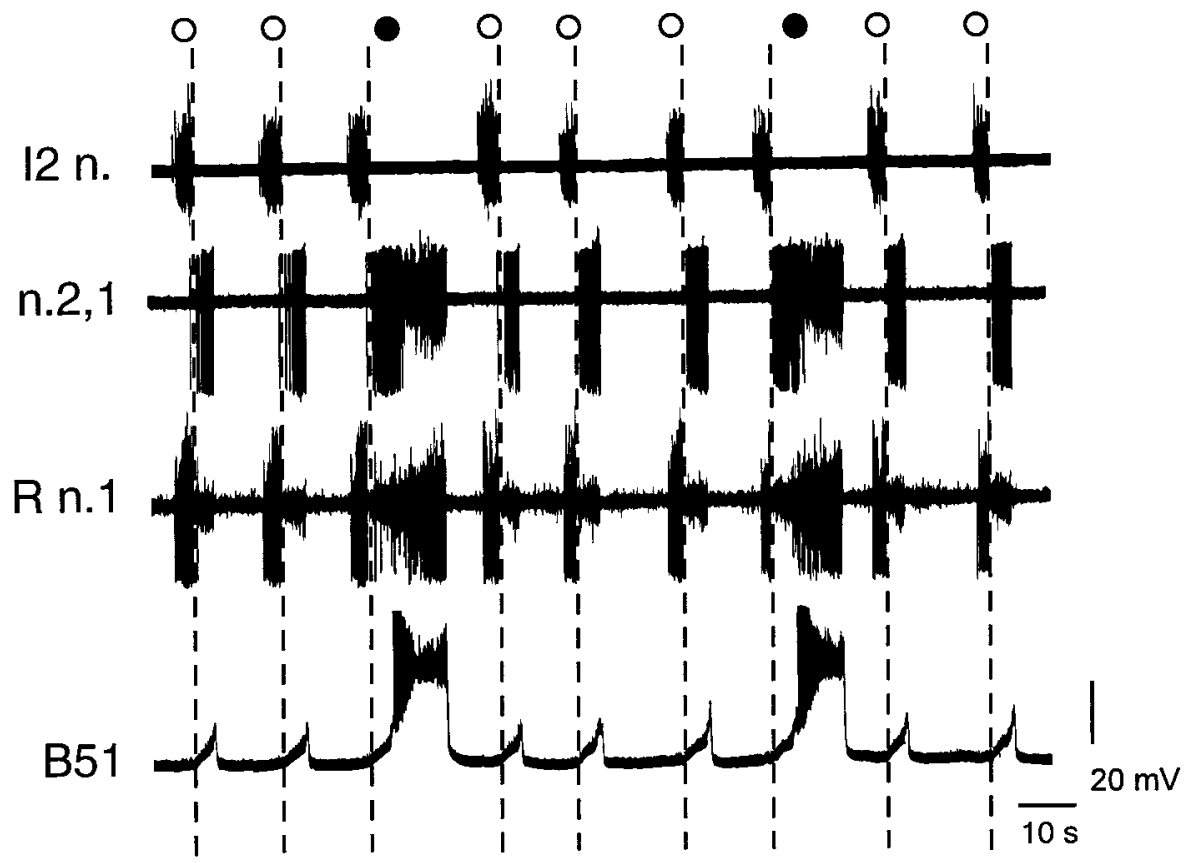

B.

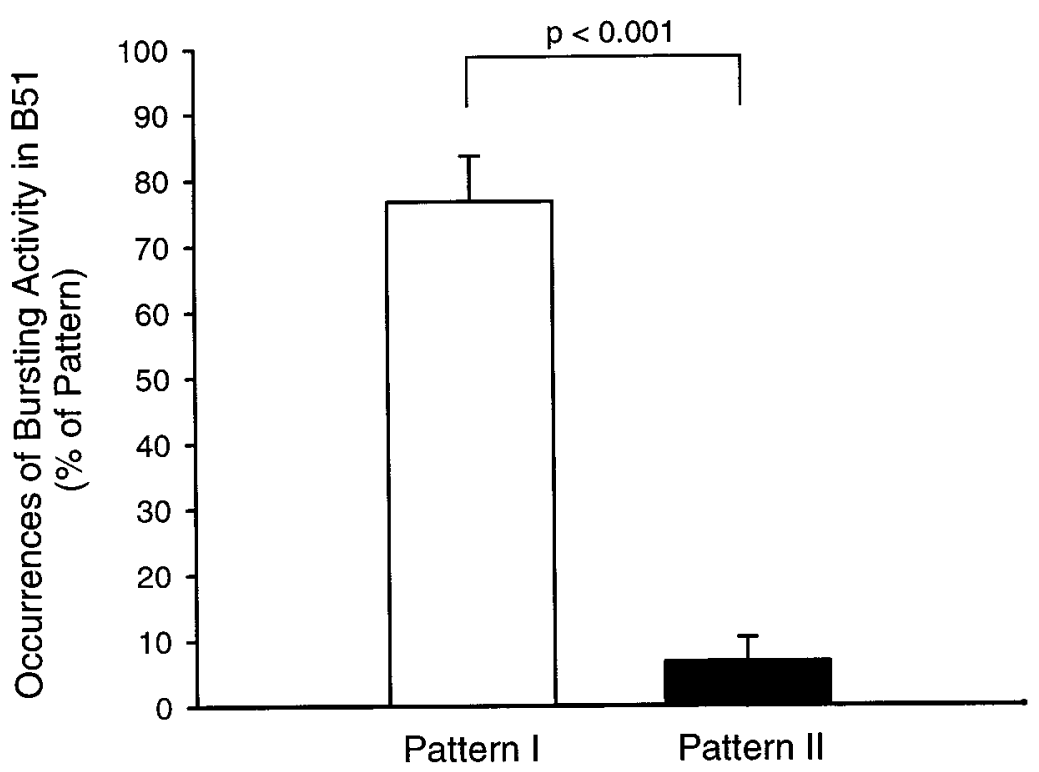

Figure 2. Probabilistic occurrences of pattern I were associated with occurrences of bursting activity in neuron B51. A, During monotonic stimulation of n.2,3, probabilistic occurrences of pattern I (pattern I, ; pattern II, $\bigcirc$ ) were associated with the dynamics of the occurrence of bursting activity in the premotor neuron B51. Bursting activity of B51 was defined as an activity higher than $4 \mathrm{~Hz}$ for $>1$ sec. $B$, Comparison between the occurrence of pattern I and pattern II with occurrence of bursting activity in B51. A large proportion of pattern I (i.e., $>70 \%$ ) co-occurred with bursting activity in B51. The proportion of pattern II co-occurring with such activity in B51 was low (i.e., $<10 \%$ ). These results were from 11 preparations in which the motor patterns and activity in a single B51 have been recorded for $1 \mathrm{hr}$ of monotonic stimulation of n.2,3. The successive activities were analyzed during this hour or until the 50th pattern. In this and the subsequent figures, the bars indicate the mean values \pm SEM.

durations varied from one preparation to another. In pattern I, the comparison of the duration of activity in B51 and the duration of the closure activity during the retraction phase indicated that both activities covaried significantly $\left(F_{1,10}=30.630 ; p<0.001\right)$ (Fig. $3 B$ ). The longer the duration of B51 activity, the longer the duration of the closure motor activity. This correlation accounted for $77 \%$ of the variation of the closure activity during the retraction phase. These results indicated that activity in B51 not only co-occurred with pattern I, but also was correlated with a key distinguishing feature of this pattern. In contrast, in intermediate patterns, a similar comparison indicated that activity in B51 was not significantly correlated with the closure motor activity during the retraction phase (data not shown; $F_{1,10}=1.867$ ). Thus, although activity in B51 co-occurred with this pattern, this activ- ity was not a determining factor for the distinguishing feature of intermediate patterns.

The comparison of the duration of activity in B51 with the duration of activity in n.2,1 indicated that these activities covaried significantly in either pattern I $\left(F_{1,10}=22.726 ; p<0.001\right)$ (Fig. $3 C$ ) or intermediate patterns (data not shown; $F_{1,10}=27.714 ; p<$ $0.001)$. These correlations accounted for $72 \%$ of the total variation of the activity in n.2,1 in pattern I (Fig. 3C) and for $75 \%$ in intermediate patterns. Thus, activity in B51 can predict the variation of the duration of the retraction phase in either motor pattern.

These results suggest that the dynamics of B51 activity can account for the variation of pattern I, and thus activity of B51 may be a key determinant for features of this pattern. Our companion 
A.

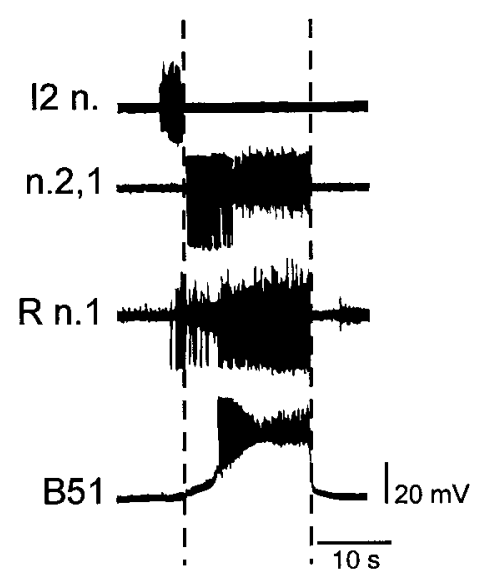

B.

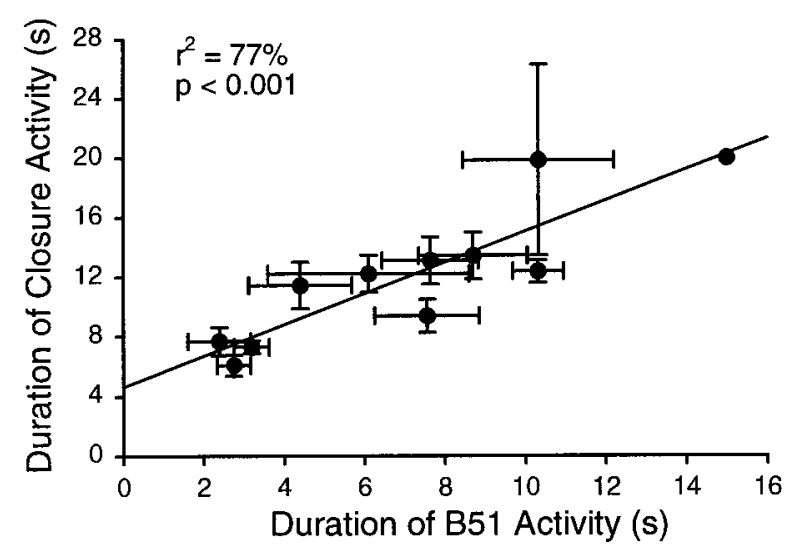

C.

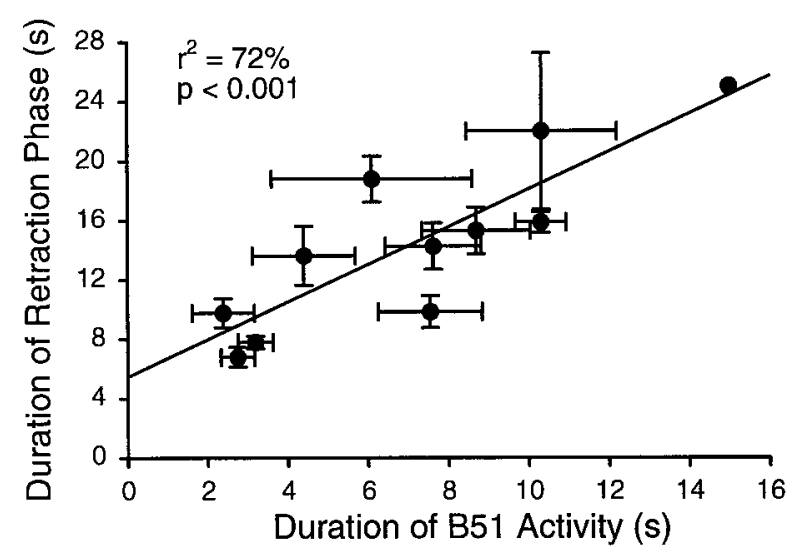

Figure 3. Correlation between activity of B51 and key features of pattern I. In pattern I, activity in B51 was associated with the large-amplitude unit activity in $\mathrm{R} \mathrm{n} .1$ that primarily (at least $50 \%$ ) occurred during a prolonged retraction phase. The vertical dashed lines represent the duration of the retraction phase $(A)$. The duration of B51 activity was significantly ( $p<$ $0.001)$ correlated with the duration of the closure motor activity that occurred during the retraction phase of pattern $\mathrm{I}(B)$ and with the duration of the retraction phase $(C)$. Each point represents the mean values of data from all occurrences of pattern I recorded in a single preparation. The regression lines and the coefficients of determination $\left(r^{2}\right)$ were calculated from the mean values from the 11 preparations described in Figure $2 B$. paper (Nargeot et al., 1999a) examines the causal role of B51 in generating the pattern. In contrast, the dynamics of activity of B51 by itself could not account for the different features of intermediate patterns. Thus, the activity of other neurons appears to be required to express the features of this pattern.

In an analog of operant conditioning, the occurrence of pattern I was selectively modified by contingent stimulation of $E$ n.2 (Nargeot et al., 1997b). Because the dynamical activity of B51 was selectively associated with the dynamics of pattern I, B51 could be a locus of the neuronal modifications induced by this contingent reinforcement.

\section{Contingent reinforcement modifies the dynamical activity of B51}

To determine whether contingent stimulation of $\mathrm{E} n .2$ on pattern I modified the dynamical activity of B51, we compared B51 activity in three groups of preparations: a contingentreinforcement group, a yoke-control group, and a control group. Each group contained eight preparations in which motor patterns and activity in B51 were recorded simultaneously. The experiments were conducted in blocks of three matched preparations (i.e., a contingent-reinforcement preparation, a yoke-control preparation, and a control preparation). These preparations were subject to the same training paradigm and the same restrictions as described earlier (Nargeot et al., 1997b). The buccal ganglia were ranked in order of their dissection and assigned to a training procedure according to the following order: contingent reinforcement, yoke control, control. This assignment was independent of any recordings of neuronal activity. Thus, there was no preferential assignment of preparations to the different groups.

In all groups of preparations, the neuronal activity was induced by monotonic $(4 \mathrm{~Hz})$ stimulation of $\mathrm{n} .2,3$. The training lasted 10 min and began with the first occurrence of pattern $\mathrm{I}$ in the contingent-reinforcement preparation (Fig. 4). The delay between the onset of the stimulation of n.2,3 and the first occurrence of pattern I was not significantly different between groups ( $H=0.789 ; \mathrm{df}=2$; contingent reinforcement, $4.6 \pm 2.2 \mathrm{~min}$; yoke control, $3.2 \pm 1.4 \mathrm{~min}$; control, $3.9 \pm 1.5 \mathrm{~min}$ ). During training, stimulation of E n.2 was used as an analog of reinforcement (Fig. $1 A)$. In the contingent-reinforcement group, to mimic the procedure of operant conditioning, phasic $(10 \mathrm{~Hz}, 6 \mathrm{sec})$ stimulation of E n.2 was made contingent on expression of pattern I (Fig. 4A). In the yoke-control group, each preparation received a paradigm of stimulation of n.2,3 and E n.2 identical to that used in the paired contingent-reinforcement preparation (Fig. $4 B$ ). Thus the timing of delivery of the stimulation of $\mathrm{E} n .2$ relative to the onset of stimulation of n.2,3 was determined by the stimulation of E n.2 in the paired contingent-reinforcement preparation rather than by the occurrence of pattern I in the yoke-control preparation. By yoking the two preparations, there is no contingent association of stimulation of E n.2 with motor patterns expressed in the yokecontrol preparation. In the control group, no stimulation of E n.2 was delivered (Fig. 4C). Because pattern I was required for contingent reinforcement, preparations (7\%) that did not express this pattern were discarded in all groups. Moreover, a minimum of five shocks to $\mathrm{E}$ n.2 were delivered in the contingentreinforcement preparations (Nargeot et al., 1997b).

The neural modifications induced by this training protocol were tested during a test period beginning immediately after the training period. This test period was composed of two successive phases. In the first test phase, which began immediately after training, no stimulation of n.2,3 was delivered. During this pe- 


\section{A. Contingent Reinforcement}

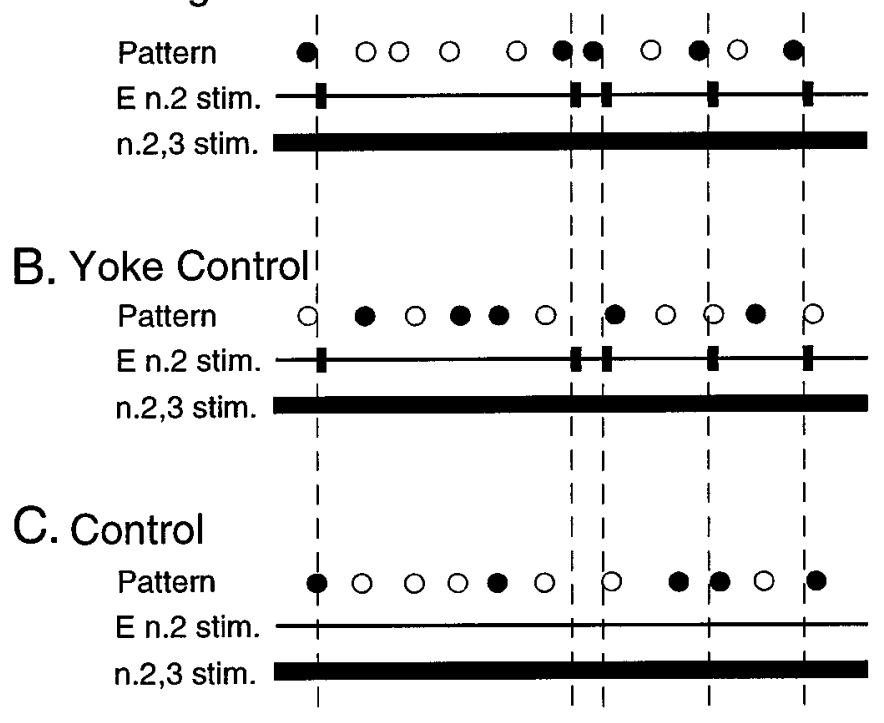

Figure 4. Training protocol for contingent reinforcement of pattern I. Experiments were conducted in blocks of three matched preparations (Contingent Reinforcement, Yoke Control, Control). In all preparations, rhythmic motor activity composed of pattern I (O) and other patterns (e.g., pattern II, $\bigcirc$ ) was induced by monotonic stimulation of n.2,3 (bold bar, n.2,3). A, Contingent reinforcement. In this preparation, a phasic (10 $\mathrm{Hz}, 6 \mathrm{sec}$ ) electrical stimulation of $\mathrm{E} n .2$ was used as an analog of reinforcement (black rectangles in E n.2) and delivered immediately after the occurrence of a pattern I. B, Yoke control. Stimulation paradigms of n.2,3 and E n.2 were identical to those in the matched contingentreinforcement preparation. However, because the occurrence of motor patterns followed different dynamics in each preparation, there was no explicit contingency of stimulation of $\mathrm{E} \mathrm{n} .2$ with pattern I (dashed lines; compare with $A$ ). $C$, Control. No stimulation of E n.2 was applied. The training period lasted $10 \mathrm{~min}$ in all preparations and began with the occurrence of the first pattern $I$ in the contingent-reinforcement preparation.

riod, we tested the membrane properties of B51 (see below). The second test phase started at various times after training (i.e., dependent on the duration of the first testing phase), but this second phase never began later than $1 \mathrm{hr}$ after training and was statistically homogenous among the three groups (contingent reinforcement, $14.0 \pm 2.5 \mathrm{~min}$; yoke control, $19.3 \pm 5.1 \mathrm{~min}$; control, $18.5 \pm 3.3 \mathrm{~min} ; H=1.757$; $\mathrm{df}=2$ ). During the second phase the monotonic stimulation of n.2,3 was restarted and continued for $20 \mathrm{~min}$. The activity of B51 and motor patterns were compared among the different groups of preparations during the last 10 min of stimulation.

To test the efficacy of the training procedure, the rhythmic motor activity expressed during this last $10 \mathrm{~min}$ test period was compared among groups. The number of occurrences of the reinforced pattern (i.e., pattern I) was significantly different among the groups $(H=8.468 ; \mathrm{df}=2 ; p<0.02)$. The occurrences of pattern I were significantly increased in the contingentreinforcement group $(10.6 \pm 1.3)$ as compared with either the yoke-control group $\left(4.5 \pm 1.5 ; q_{3}=3.775 ; p<0.025\right)$ or the control group $\left(5.0 \pm 1.2 ; q_{2}=4.864 ; p<0.001\right)$. Thus, the enhancement of pattern I depended on the contingency of stimulation of E n.2 with pattern I. Moreover, no significant change in the occurrences of pattern I was observed between the yoke-control and the control groups $\left(q_{2}=0.743\right)$, indicating a lack of noncontingent effects of stimulation of E n.2. Finally, in the same preparations and during the same test period, no significant change was observed among the different groups for the occurrences of the nonreinforced patterns (i.e., pattern II and intermediate patterns; $H=0.821 ; \mathrm{df}=2$; contingent reinforcement, $8.2 \pm 2.3$; yoke control, $6.8 \pm 1.0$; control, $5.6 \pm 1.5)$ and incomplete patterns $(H=1.185$; df $=2$; contingent reinforcement, $1.5 \pm 1.1$; yoke control, $0.5 \pm 0.3$; control, $1.4 \pm 0.6$ ). Thus, only the reinforced pattern was modified by contingent reinforcement. This contingent-dependent enhancement of a designated motor pattern was similar to that reported previously (Nargeot et al., 1997b, 1999b; Baxter et al., 1998).

In addition, activity in B51 was compared among the three groups of preparations during the same test period (Fig. 5). The occurrences of bursting activity in B51 (i.e., the activity higher than $4 \mathrm{~Hz}$ for $>1 \mathrm{sec}$ ) were significantly different among groups $(H=6.865 ; \mathrm{df}=2 ; p<0.035)$ (Figs. 5, 6). This difference resulted from an enhancement of the occurrences of this bursting activity in the contingent-reinforcement group as compared with either the control $\left(q_{3}=3.550 ; p<0.05\right)$ or yoke-control group $\left(q_{2}=\right.$ 3.862; $p<0.01)$. No significant difference was recorded between the occurrences of this bursting activity in control and yokecontrol groups $\left(q_{2}=1.411\right)$. Thus, contingent reinforcement of pattern I appeared to modify the level of activity in B51 that was specifically related to pattern I.

These results indicated that the enhancement of the buccal motor output by contingent reinforcement was correlated with a change in the dynamical activity of B51. Such modification of the dynamical activity of B51 could result from changes in membrane properties of B51 itself or from changes in presynaptic inputs to B51 or both. To investigate whether B51 is a locus of neuronal modifications induced by contingent reinforcement of pattern I, we tested for changes in its intrinsic membrane properties.

\section{Contingent-dependent change in regenerative properties of B51}

The regenerative membrane properties of B51 allow it to switch between inactive and active states in which the cell fires a burst of action potentials (Plummer and Kirk, 1990). This switching can be induced by a brief depolarization of the cell that allows it to reach the threshold for eliciting a plateau potential. This plateau potential is characterized by a spiking activity that outlasts the duration of the initial depolarization. During current pulses of progressively increasing intensity, B51 expresses either no activity (i.e., the pulse induced a depolarization that was below the threshold to elicit the plateau potential) or a strong burst of activity that outlasts the stimulus (i.e., when the pulse induced a depolarization that was above the threshold to elicit the plateau potential) (Fig. 7).

In the same groups of preparations described previously (i.e., contingent reinforcement, yoke control, control), the threshold to elicit the bursting activity in B51 was determined before and immediately after training (i.e., during the first test period). This threshold was quantified as the minimum amount of current necessary to elicit an activity that outlasts the current pulse for each of two successive pulses of same intensity. In all preparations, the resting membrane potential in B51 was held at $-60 \mathrm{mV}$ during testing. A series of current pulses $(5 \mathrm{sec})$ were delivered from $1 \mathrm{nA}$ and increased in steps of $1 \mathrm{nA}$ until the threshold was reached. To prevent rhythmic activity and synaptic input to B51, no stimulation of n.2,3 was used during this test period. The current threshold for eliciting the bursting activity depended on the cell properties but also on the cell size. Thus, to characterize 


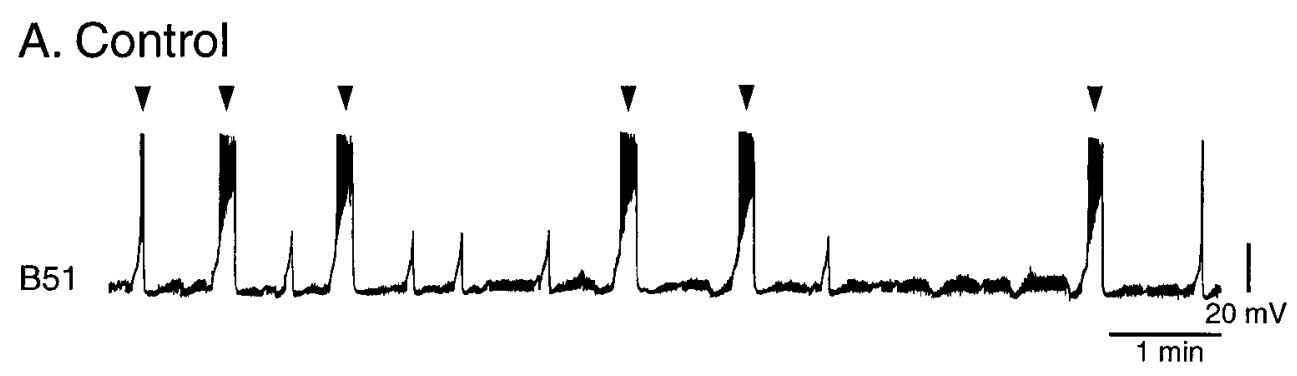

B. Contingent Reinforcement

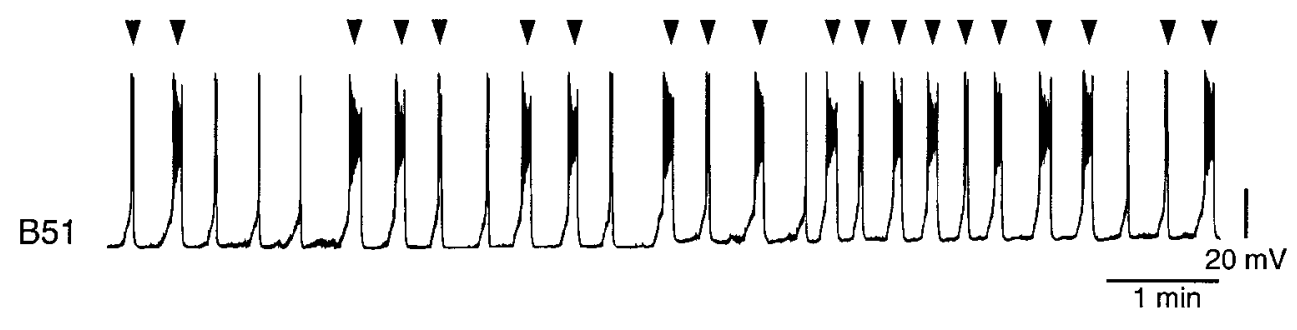

Figure 5. Contingent-dependent enhancement of the occurrences of the bursting activity in B51. Recording of activity in B51 during a 10 min test period of monotonic stimulation of n.2,3 in control $(A)$, contingent-reinforcement $(B)$, and yoke-control $(C)$ preparations during a $10 \mathrm{~min}$ test phase after training. The number of occurrences of the bursting activity in B51 (indicated by black triangles and as defined in the legend of Fig. 2) was higher in the contingentreinforcement preparation than in the control and yoke-control preparations.

\section{Yoke Control}

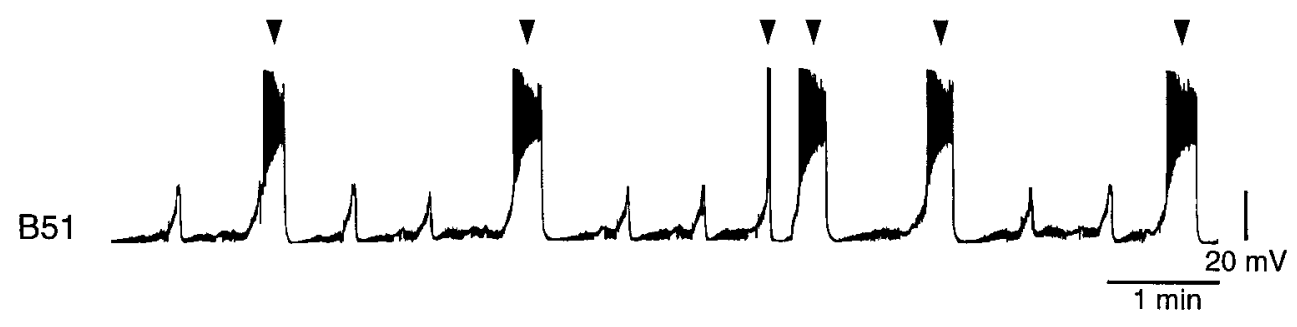

the effect of training on membrane properties of B51, the threshold values were determined before and after training in same preparations.

Figure 7 illustrates the responses in B51 to depolarizing current pulses in a control (Fig. $7 A$ ), a contingent-reinforcement (Fig. $7 B$ ), and a yoke-control preparation (Fig. $7 C$ ). In these three different preparations and before the training period, the threshold for inducing bursting activity in B51 was similar (i.e., $3 \mathrm{nA}$ ). After training, however, this threshold changed as compared with both the pretraining responses and the different training procedures. In the contingent-reinforcement preparation, less current was necessary to elicit the bursting activity in B51 after training than before (Fig. 7B). In contrast, in the yoke-control and control preparations, higher current intensities were required to elicit bursts of activity in B51 after the training period than before (Fig. $7 A, C)$. Because this increase of threshold was observed in the control group, it could not be related to the effect of the reinforcement (i.e., stimulation of E n. 2 was not delivered in this group). Rather, this effect might be related in part to the stimulation of n.2,3 used during all three training paradigms.

These observations were supported by statistical comparison of the changes in burst threshold in B51 (pretraining vs post-training values) normalized to the pretraining values (Fig. 8). Changes in the burst threshold in B51 were significantly different among groups $(H=10.564$; $\mathrm{df}=2 ; p<0.005)$. The modification was significantly different in the contingent-reinforcement group as compared with either the control $\left(q_{3}=4.025 ; p<0.025\right)$ or the yoke-control group $\left(q_{2}=5.161 ; p<0.001\right)$. In contrast, these modifications were not significantly different between the control and the yoke-control group $\left(q_{2}=0.817\right)$. Thus, the contingent association of stimulation of E n.2 with pattern I decreased the threshold for eliciting plateau potential in B51.

These results indicated that contingent reinforcement of pattern I increased both the occurrences of pattern I and the excitability of B51. This contingent-dependent enhancement in B51 excitability may have resulted from changes in the intrinsic regenerative membrane properties of the cell. We investigated whether these modifications also were associated with changes in the membrane resistance of B51.

\section{Contingent-dependent change in the input resistance of B51}

The input membrane resistance of B51 was tested in the same groups of preparations described previously (i.e., contingent reinforcement, yoke control, and control). The input resistance was evaluated by injecting brief $(5 \mathrm{sec})$ hyperpolarizing $(-5 \mathrm{nA})$ current pulses before training and during the first test period. In all cases, the resting membrane potential of B51 was held at -60 $\mathrm{mV}$. Figure 9 illustrates sample responses to identical current pulses for a control preparation (Fig. 9A), a contingentreinforcement preparation (Fig. $9 B$ ), and a yoke-control preparation (Fig. 9C). In these three typical examples, current pulses before training elicited similar deflections in the membrane potential of B51. After training, however, the current pulses induced a larger deflection in the contingent-reinforcement preparation (Fig. 9B). In contrast, responses of B51 elicited after the training 
N.S.

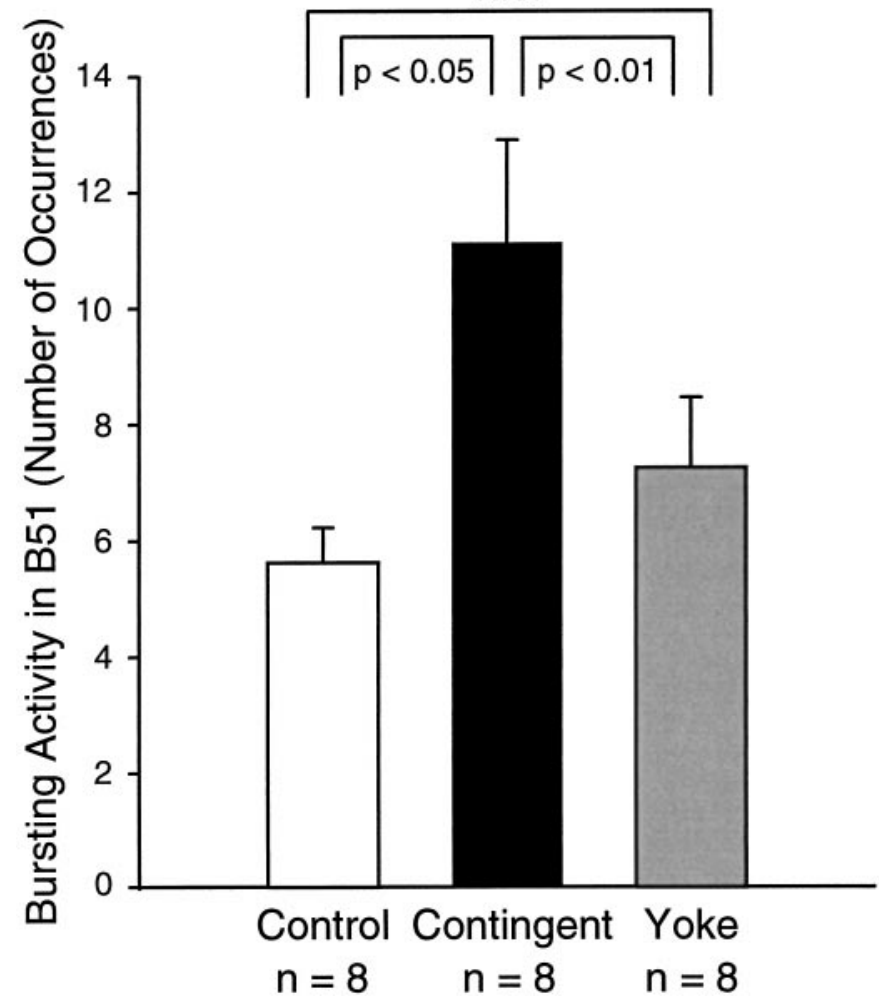

Figure 6. Comparison of occurrences of the bursting activity of B51. A significantly higher number of occurrences of the bursting activity in B51 (as defined in legend of Fig. 2) was expressed during a 10 min test period, in the contingent-reinforcement group (black bar, $n=8$ ) as compared with the control (white bar, $n=8 ; p<0.05$ ) or yoke-control group ( gray bar, $n=8 ; p<0.01)$. No significant difference (N.S.) in the number of occurrences of B51 bursting activity was observed between the yokecontrol and control groups.

period in the control or yoke-control preparations were only slightly modified (Fig. 9A,C).

These observations were supported by statistical comparison among groups (Fig. 10). There was a significant difference among the three groups of preparations $(H=7.604$; $\mathrm{df}=2 ; p<0.025)$. The contingent-reinforcement group expressed a greater increase in the input resistance of B51 than in either control $\left(q_{2}=5.013\right.$; $p<0.001)$ or yoke-control group $\left(q_{3}=3.375 ; p<0.05\right)$. No significant difference was observed between the control and yokecontrol groups $\left(q_{2}=0\right)$. Thus, B51 input resistance was increased by stimulation of $\mathrm{E} n .2$, and this increase resulted from the contingent association of this stimulation with pattern I.

The results of the present study suggest that the modification of the dynamics of B51 by contingent reinforcement of pattern I may result from changes in the intrinsic membrane properties of this cell. Further studies will be necessary to confirm this possibility and to determine whether changes in cells presynaptic to B51 also contribute to its enhanced activity after contingent reinforcement. It will also be important to identify the specific conductances that are modified by training and the ways in which those modifications contribute to the changes in input resistance and excitability of B51.

\section{DISCUSSION}

Although a considerable body of evidence is accumulating on the cellular mechanisms of a form of associative learning, classical conditioning (Kandel and Schwartz, 1982; Carew and Sahley, 1986; Byrne, 1987; Thompson, 1988; Beggs et al., 1998), much less is known about another form of associative learning, operant conditioning. In operant conditioning, the delivery of reinforcement depends on the probabilistic occurrence of a particular behavior. This contingent association modifies the probability of occurrence of the behavior. Thus, understanding the neuronal processes underlying probabilistic occurrence of behaviors and their modification by contingent reinforcement is fundamental to characterizing the neuronal basis of operant conditioning.

In the present study, we found that the probabilistic occurrences of different motor patterns (i.e., pattern I, pattern II, intermediate patterns) in the isolated buccal ganglia were correlated with the dynamical switching between inactive and active states of a previously identified neuron, B51 (Plummer and Kirk, 1990). Changes in the buccal motor output by contingent reinforcement were accompanied by changes in the dynamical activity of B51 and in the intrinsic membrane properties of B51. The switches between states of B51 appeared to be centrally programmed, in part, by the intrinsic properties of the cell (see below). Although behaviors can be generated by centrally programmed activity, little is known about the modifications of these central processes by contingent reinforcement. Such knowledge could provide a basis for comparison of neuronal mechanisms of operant conditioning with classical conditioning.

\section{B51 is an element of the buccal CPG}

CPGs are neuronal networks that centrally (i.e., do not require patterned sensory input) organize the rhythms and relative timing of patterned neuronal activity (Friesen et al., 1976; Delcomyn, 1980; Grillner, 1985; Selverston and Moulins, 1985; Lydic, 1989; Bianchi et al., 1995; Grillner et al., 1997). Neurons that participate in a CPG have two characteristic features (Selverston and Moulins, 1985). First, they express a rhythmic activity whose frequency can be related to the frequency of motor pattern generated by the CPG. Second, experimental manipulation of their firing is able to modify the rhythm generated by the CPG. This second feature indicates that such a neuron must be synaptically connected to other elements of the CPG. B51 appears to have these two features. The rhythmic activity of B51 is related to the occurrences of pattern I, and experimental manipulation of activity of B51 modifies the rhythm generated spontaneously by the CPG or can reset the occurrences of pattern I (Plummer and Kirk, 1990; Nargeot et al., 1997a, 1999). In addition, B51 can synaptically drive or be driven by other neurons of the CPG (Plummer and Kirk, 1990; Nargeot et al., 1999). Thus, B51 appears to participate in the CPG that generates pattern I.

B51 is also a sensory neuron (Evans and Cropper, 1998). In our isolated preparation, however, its sensory function was not relevant (i.e., the peripheral nerve in which B51 projects its axon was not stimulated). Rather, activity of B51 was part of the central processes that organized the probabilistic occurrences of pattern I. The neuronal mechanisms by which B51 contributes to the expression of pattern $\mathrm{I}$ is examined in our companion paper (Nargeot et al., 1999a).

\section{Probabilistic CPG reconfiguration}

In contrast to neurons of the buccal CPG that are active during each successive motor pattern (Susswein and Byrne, 1988; Hurwitz and Susswein, 1996; Hurwitz et al., 1996, 1997), B51 was only intermittently active during monotonic stimulation of n.2,3. When B51 was active, it fired in phase with motor patterns, but the 


\section{A. Control}

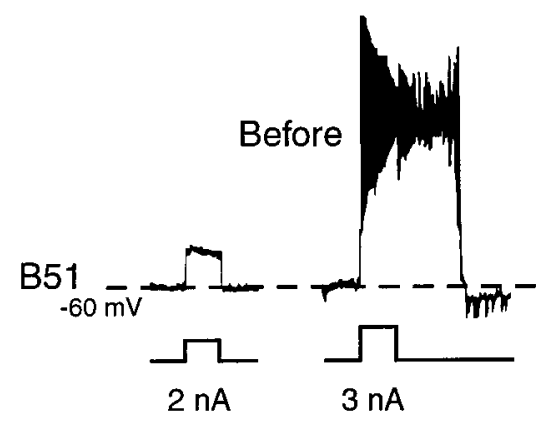

B. Contingent Reinforcement

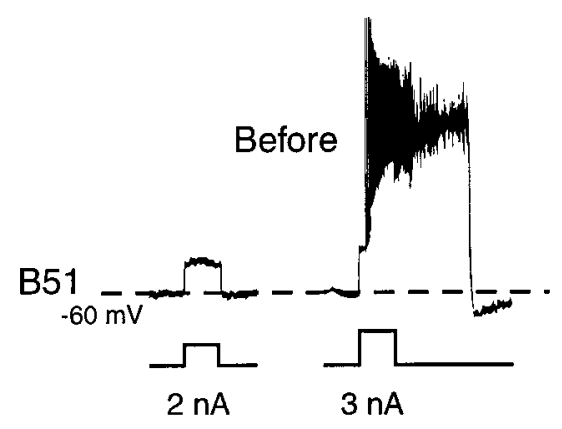

Figure 7. Contingent-dependent change in burst threshold of B51. Depolarizing current pulses (5 $\mathrm{sec})$ were injected into B51 before and after the training period in control $(A)$, contingentreinforcement $(B)$, and yoke-control $(C)$ preparations. In all cases, the resting membrane potential of $\mathrm{B} 51$ was held at $-60 \mathrm{mV}$ (dashed lines). Before training, a minimum of $3 \mathrm{nA}$ was necessary to elicit a plateau potential (defined as an activity that outlasts the current pulse duration) in each of the three preparations. After training, the same current pulse failed to elicit a plateau potential in B51 in the control and yoke-control preparations. Thus, in these preparations the burst threshold in B51 was increased. In contrast, a less intense current $(2 \mathrm{nA})$ elicited the plateau potential after training in the contingentreinforcement preparation. Thus, the contingentreinforcement paradigm decreased burst threshold in B51. No stimulation of n.2,3 was delivered during the testing procedure.

\section{Yoke Control}

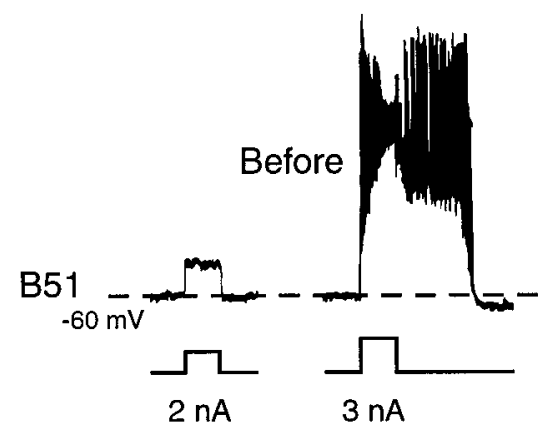

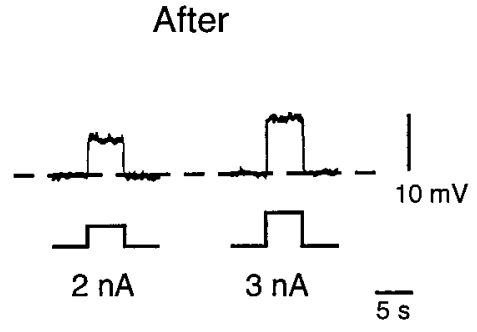
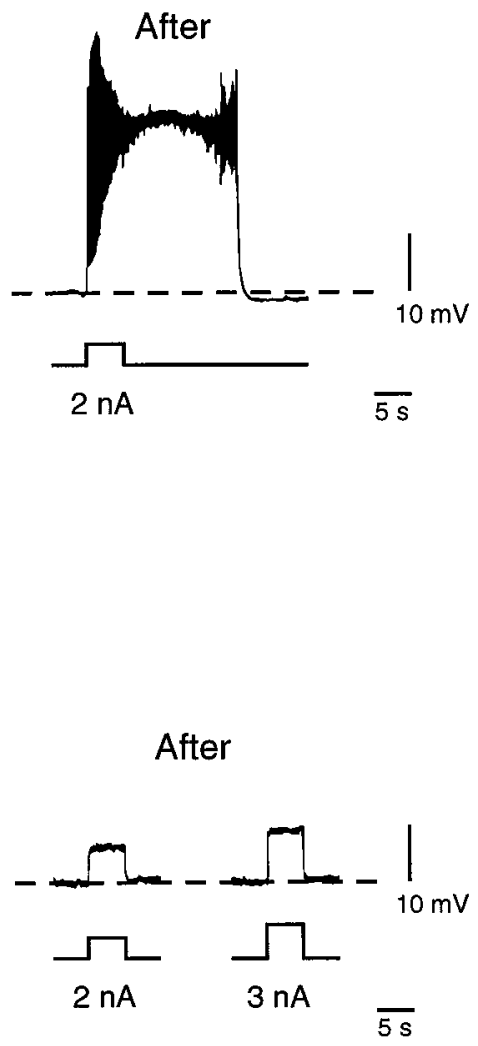

occurrence of its activity did not appear to be predictable. Several arguments suggest that this probabilistic recruitment of activity of B51 did not have a peripheral origin (i.e., was not determined by afferent pathways to the CPG). First, in the isolated buccal ganglia, the stimulation of n.2,3 that was used to induce motor patterns was monotonic and thus unlikely to contain dynamical cues related to the dynamical activity of B51. Second, during this unchanging stimulation, activity of B51 occurred repetitively with variable interburst intervals, minimizing the possibility that its dynamics resulted from adaptation or fatigue of the stimulus pathway. Third, B51, like some other cells in the buccal CPG (e.g., B34) (Hurwitz et al., 1997), can be spontaneously active or inactive during buccal motor output (Plummer and Kirk, 1990). Thus, nerve stimulation induced a state permissive for dynamical activity of B51, but the stimulation did not organize this activity.

Our results support the hypothesis that the probabilistic re- cruitment of B51 was centrally programmed. CPGs organize rhythms of neuronal activity as a result of the intrinsic membrane properties and the synaptic connections of their constituent neurons (Russell and Hartline, 1978; Susswein and Byrne, 1988; Getting, 1989; Rossignol and Dubuc, 1994; Marder and Calabrese, 1996; Canavier et al., 1997). Such properties could underlie the dynamical activity of B51. We do not know whether the recruitment of B51 in the buccal CPG was determined by synaptic inputs to the cell, by the intrinsic membrane properties of B51, or by a combination of the two. Neurons from the CPG provide a synaptic drive for B51 (Plummer and Kirk, 1990; Nargeot et al., 1999), and other cells with comparable dynamical activity have been identified in the buccal ganglia (Hurwitz et al., 1997). Such cells could form a network interacting within the CPG and such interactions could underlie the switching of neuronal activity between different patterns or states (Hooper 


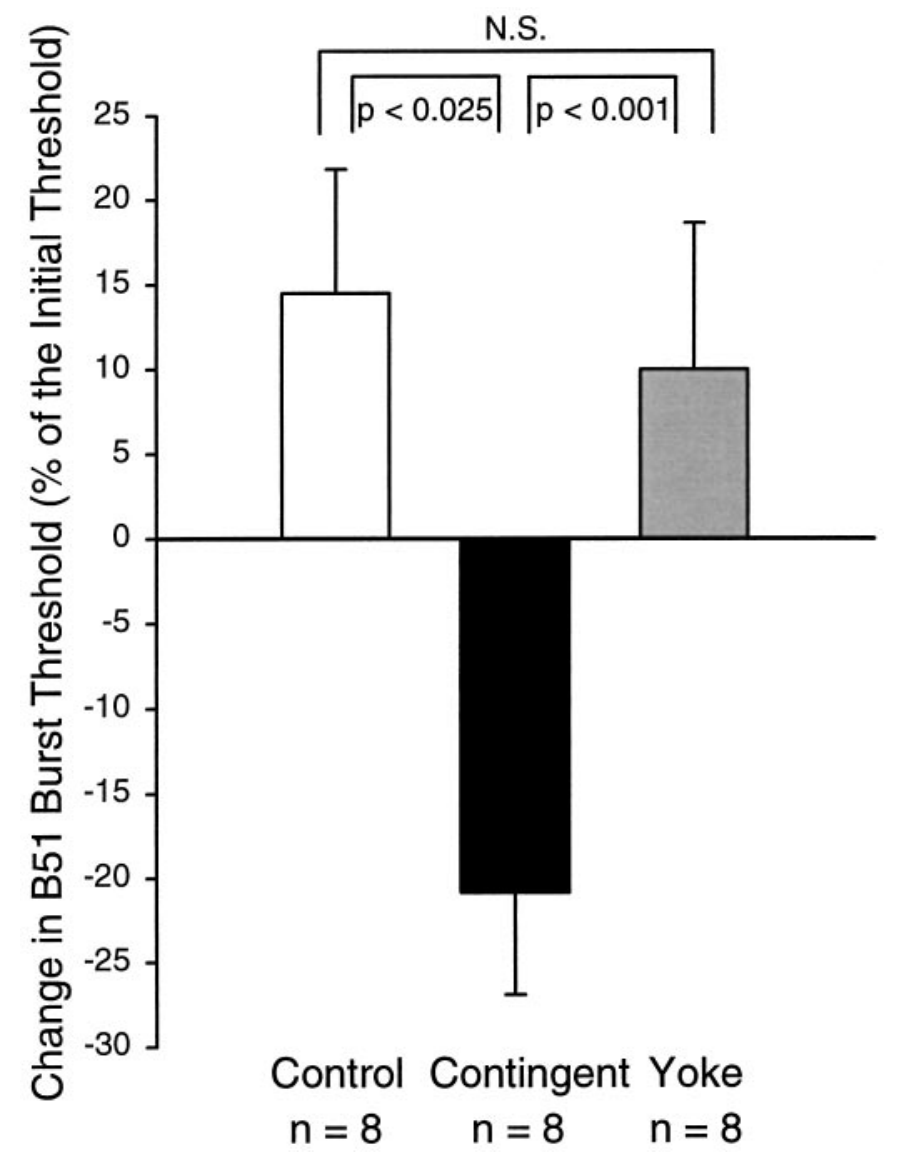

Figure 8. Comparison of changes in B51 burst threshold. Changes in burst threshold (i.e., the difference between the after and before threshold values normalized to the before training value) were observed as an increase in the control $(n=8)$ and the yoke-control $(n=8)$ groups and as a decrease in the contingent-reinforcement $(n=8)$ group. These changes were significantly different between the contingent-reinforcement group and either the control $(p<0.025)$ or the yoke-control group $(p<$ 0.001 ). No significant (N.S.) difference was observed between the control and the yoke-control groups.

and Moulins, 1989; Weimann and Marder, 1994). However, contingent reinforcement that seems to modify the intrinsic membrane properties of B51 modified the functional recruitment of B51. Thus, although synaptic inputs may contribute, changes in the intrinsic properties of B51 are also one of the determinants of the probabilistic activity of B51.

It is already known that CPGs are not static structures composed of fixed neuronal elements that produce a stereotyped pattern of activity. The number of active neurons in CPGs can be modified to produce different patterns. It is generally believed that these network reconfigurations are elicited by changes in sensory stimuli that can elicit or modify the modulatory processes that control the network functioning (Getting and Dekin, 1985; Hooper et al., 1990; Katz and Harris-Warrick, 1991; Meyrand et al., 1994) (also see Harris-Warrick and Marder, 1991; Pearson, 1993; Marder and Calabrese, 1996). Sensory pathways can induce changes in synaptic connections and/or the cellular properties of neurons and thereby functionally exclude or recruit neurons into a CPG (Hooper and Moulins, 1989; Dickinson et al., 1990; Meyrand et al., 1991; Nargeot and Moulins, 1997) (also see Dickinson and Moulins, 1992).

\section{A. Control}
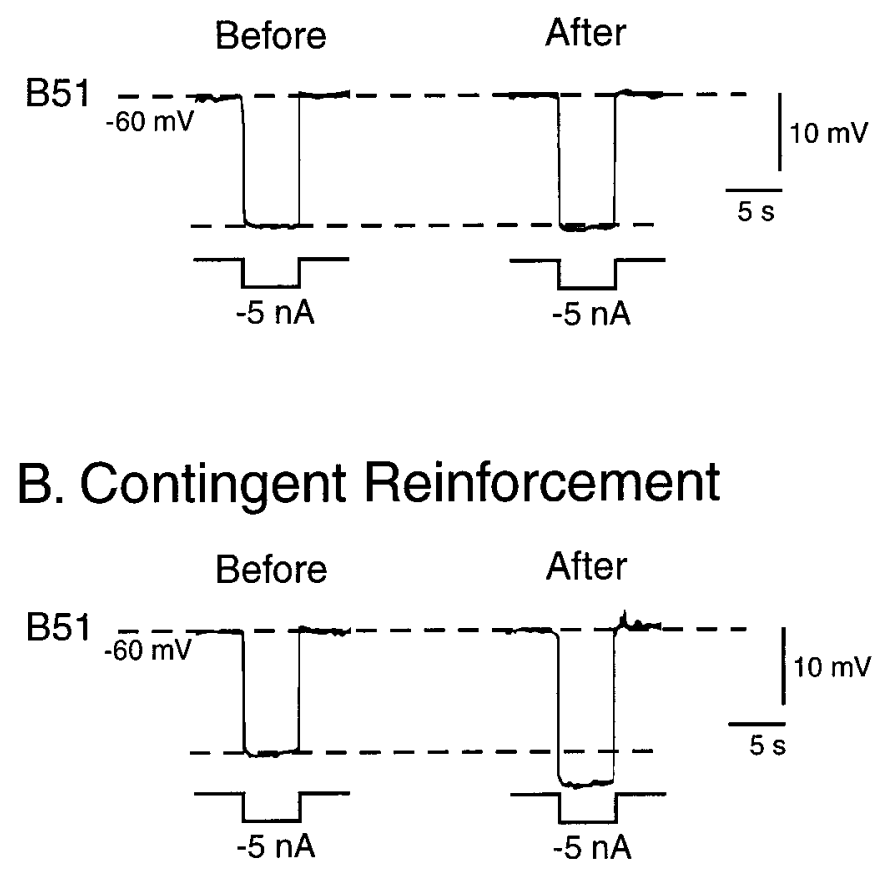

\section{Yoke Control}

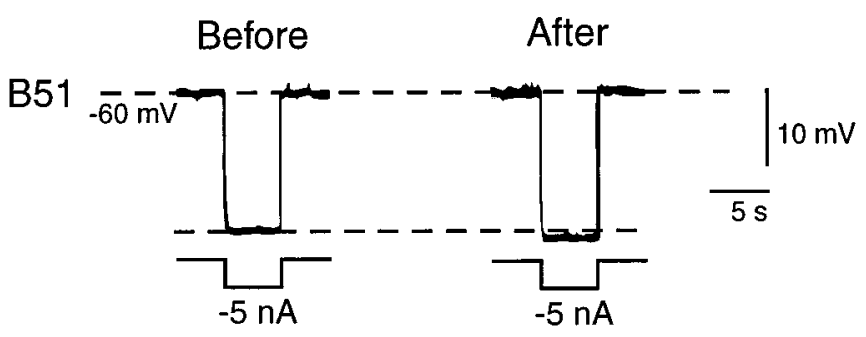

Figure 9. Contingent-dependent change in B51 input resistance. Hyperpolarizing current pulses $(-5 \mathrm{nA} ; 5 \mathrm{sec})$ were injected into B51 before and after the training period in a control $(A)$, a contingent-reinforcement $(B)$, and a yoke-control $(C)$ preparation. In all cases, the resting membrane potential of $\mathrm{B} 51$ was maintained at $-60 \mathrm{mV}$ (top dashed line). In the control and yoke-control preparations, the responses induced by a same current pulse were only slightly increased after the training protocol (bottom dashed line). In the contingent-reinforcement preparation, the current pulse induced a larger response after training, which was indicative of an increase in the input resistance of B51. No stimulation of n.2,3 was delivered during the testing procedure.

Our data suggest that the probabilistic recruitment of neurons in CPGs can be determined by the intrinsic properties of the constituent neurons rather than by changes in sensory stimuli. These data extend the concept of functional reconfiguration of CPGs by illustrating the role of central networks and cell properties in organizing these reconfigurations. Such dynamical network reconfigurations could be a central neuronal mechanism underlying changes in the probabilistic occurrences of motor patterns that are associated with reinforcement in operant conditioning. 
N.S.

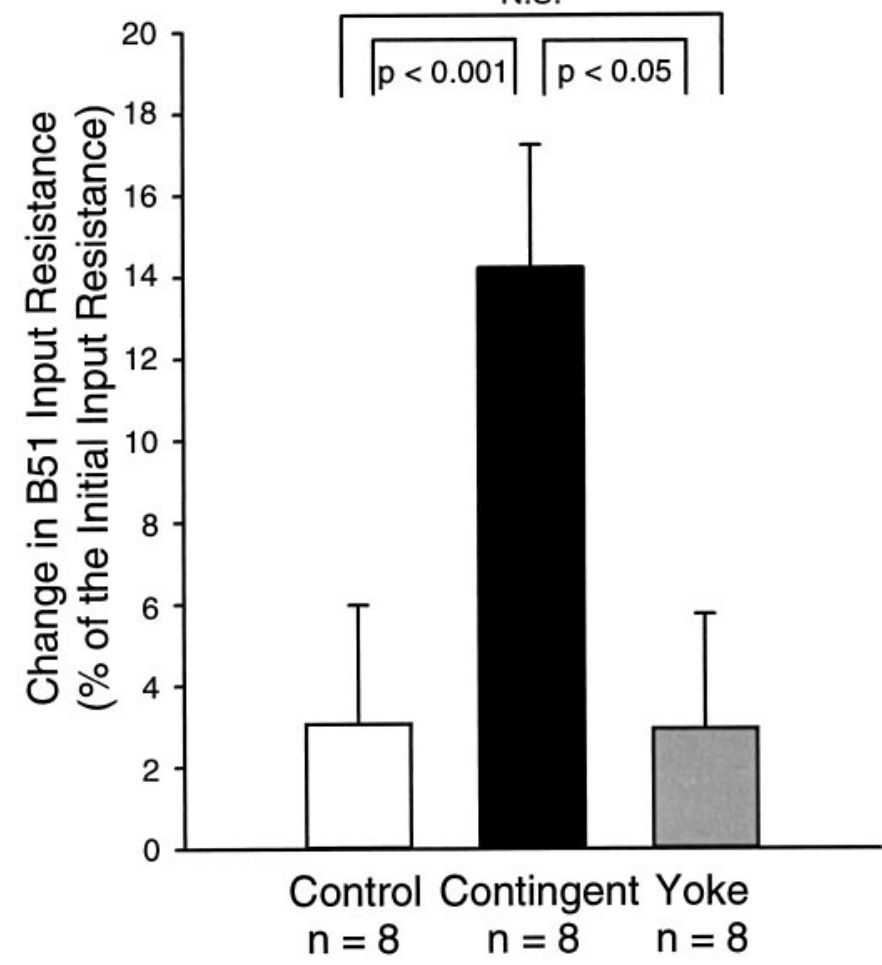

Figure 10. Comparison of changes in B51 input resistance. The change in the input resistance of B51 after training was significantly greater in the contingent-reinforcement group $(n=8)$ as compared with the control $(n=8 ; p<0.001)$ or the yoke-control group $(n=8 ; p<0.05)$. No significant (N.S.) difference was observed between the control and the yoke-control groups.

\section{Contingent-dependent plasticity of intrinsic cellular properties}

The dynamical activity of B51 can be modified by an analog of operant conditioning. This modification was associated with changes in the excitability of B51 and its input resistance. Previous studies have investigated the cellular and synaptic modifications associated with operant conditioning (Woollacott and Hoyle, 1977; Hoyle, 1979, 1982; Jaffard and Jeantet, 1981; Skelton et al., 1987; Mahajan and Desiraju, 1988; Carp and Wolpaw, 1994; Feng-Chen and Wolpaw, 1996; Spencer et al., 1996). Some of these studies have found that contingent reinforcement modified the graded increase in firing frequency in response to increasing membrane depolarizations. Such changes in cell excitability can be induced by other forms of learning as well (Brons and Woody, 1980; Crow and Alkon, 1980; Walters et al., 1983; Disterhoft et al., 1986).

In the present study, we investigated membrane properties that could underlie a contingent association in operant conditioning. The modifications of excitability in B51 appear to involve changes in the intrinsic membrane properties that govern the probability of initiating plateau potentials. Similar regenerative properties have been described in vertebrates and invertebrates (Russell and Hartline, 1978; Llinas, 1988; Susswein and Byrne, 1988; Kiehn, 1991; Bianchi et al., 1995; Russo and Hounsgaard, 1996). These regenerative membrane properties allow neurons and central networks to switch between expression of different patterned activity (Getting, 1989; Hooper and Moulins, 1989; Bianchi et al., 1995; Marder and Calabrese, 1996; Canavier et al., 1997; Nargeot et al., 1999a). Thus, these properties can constitute a central process underlying the probabilistic occurrences of neuronal activity that do not necessitate a sensory trigger. Regenerative membrane properties can be modified by afferent input (Dickinson and Nagy, 1983; Llinas and Yarom, 1986; Levitan and Levitan, 1988; Cazalets et al., 1990; Plummer and Kirk, 1990; Bal et al., 1994; Turrigiano et al., 1994; Marder et al., 1996) (also see Harris-Warrick and Marder, 1991; Hultborn and Kiehn, 1992; Byrne et al., 1993). Thus, the modifications of these conductances could be a cellular mechanism by which contingent reinforcement modifies the probabilistic occurrences of a designated behavior in operant conditioning.

\section{REFERENCES}

Bal T, Nagy F, Moulins M (1994) Muscarinic modulation of a patterngenerating network: control of the neuronal properties. J Neurosci 14:3019-3035.

Baxter DA, Nargeot R, Patterson GW, Byrne JH (1998) A dopamine antagonist (ergonovine) impaired the enhancement of motor patterns by contingent reinforcement in the isolated buccal ganglia of Aplysia. Soc Neurosci Abstr 24:1891.

Beggs JM, Brown TH, Byrne JH, Crow T, LeDouz JE, LeBar K, Thompson RF (1998) Learning and memory: basic mechanisms. In: Fundamental neuroscience (Zigmond MJ, Bloom FE, Landis SC, Roberts JL, Squire LR, eds), pp 1411-1454. San Diego: Academic.

Bianchi AL, Denavit-Saubié M, Champagnat J (1995) Central control of breathing in mammals: neuronal circuitry, membrane properties, and neurotransmitters. Physiol Rev 75:1-45.

Booker R, Quinn WG (1981) Conditioning of leg position in normal and mutant Drosophila. Proc Natl Acad Sci USA 78:3940-3944.

Brons JF, Woody CD (1980) Long-term changes in excitability of cortical neurons after Pavlovian conditioning and extinction. J Neurophysiol 44:605-615.

Byrne JH (1987) Cellular analysis of associative learning. Physiol Rev 67:329-439.

Byrne JH, Zwartjes R, Homayouni R, Critz SD, Eskin A (1993) Roles of second messenger pathways in neuronal plasticity and in learning and memory. Adv Second Messenger Phosphoprotein Res 27:47-108.

Canavier CC, Butera RJ, Dror RO, Baxter DA, Clark JW, Byrne JH (1997) Phase response characteristics of model neurons determine which patterns are expressed in a ring circuit model of gait generation. Biol Cybern 77:367-380.

Carew TJ, Sahley CL (1986) Invertebrate learning and memory: from behavior to molecules. Annu Rev Neurosci 9:435-487.

Carp JS, Wolpaw JR (1994) Motoneuron plasticity underlying operantly conditioned decrease in primate H-reflex. J Neurophysiol 72:431-442.

Cazalets J-R, Nagy F, Moulins M (1990) Suppressive control of the crustacean pyloric network by a pair of identified interneurons. II. Modulation of the neuronal properties. J Neurosci 10:458-468.

Church PJ, Lloyd PE (1991) Expression of diverse neuropeptide cotransmitters by identified motor neurons in Aplysia. J Neurosci 11:618-625.

Church PJ, Lloyd PE (1994) Activity of multiple identified motor neurons recorded intracellularly during evoked feeding like motor programs in Aplysia. J Neurophysiol 72:1794-1809.

Church PJ, Cohen KP, Scott ML, Kirk MD (1991) Peptidergic motoneurons in the buccal ganglia of Aplysia californica: immunocytochemical, morphological and physiological characterizations. J Comp Physiol [A] 168:323-336.

Colwill RM, Goodrum K, Martin A (1997) Pavlovian appetitive discriminative conditioning in Aplysia californica. Anim Learn Behav 25:268276.

Cook DG, Carew TJ (1986) Operant conditioning of head-waving in Aplysia. Proc Natl Acad Sci USA 83:1120-1124.

Cropper EC, Kupfermann I, Weiss KR (1990) Differential firing patterns of the peptide-containing cholinergic motor neurons B15 and B16 during feeding behavior in Aplysia. Brain Res 522:176-179.

Crow TJ, Alkon DL (1980) Associative behavioral modification in Hermissenda: cellular correlates. Science 209:412-414.

Delcomyn F (1980) Neuronal basis of rhythmic behavior in animals. Science 210:492-498.

Dickinson PS, Moulins M (1992) Interactions and combinations between 
different networks in the stomatogastric nervous system. In: Dynamic biological networks (Harris-Warrick RM, Marder E, Selverston AI, Moulins M, eds), pp 139-160. Cambridge, MA: MIT.

Dickinson PS, Nagy F (1983) Control of a central pattern generator by an identified modulatory interneurone in crustacea. II. Induction and suppression of plateau properties in pyloric neurones. J Exp Biol 105:59-82.

Dickinson PS, Mecsas C, Marder E (1990) Neuropeptide fusion of two motor-pattern generator circuits. Nature 344:155-158.

Disterhoft JF, Coulter DA, Alkon DL (1986) Conditioning-specific membrane changes of rabbit hippocampal neurons measured in vitro. Proc Natl Acad Sci USA 83:2733-2737.

Evans CG, Cropper EC (1998) Proprioceptive input to feeding motor programs in Aplysia. J Neurosci 18:8016-8031.

Feng-Chen KC, Wolpaw JR (1996) Operant conditioning of H-reflex changes synaptic terminals on primate motoneurons. Proc Natl Acad Sci USA 93:9206-9211.

Fitzgerald KK, Takacs CA, Carew TJ (1997) Nonassociative and associative modification of head-waving produced by aversive tentacular stimuli in Aplysia. Learn Mem 3:366-375.

Friesen WO, Poon M, Stent GS (1976) An oscillatory neuronal circuit generating a locomotor rhythm. Proc Natl Acad Sci USA 73:3734-3738.

Getting PA (1989) Emerging principles governing the operation of the neural networks. Annu Rev Neurosci 12:185-204.

Getting PA, Dekin MS (1985) Tritonia swimming: a model system for integration within rhythmic motor systems. In: Model neural networks and behavior (Selverston AI, ed), pp 3-20. New York: Plenum.

Green CS, Soffe SR (1996) Transitions between two different motor patterns in Xenopus embryos. J Comp Physiol [A] 178:279-291.

Grillner S (1985) Neurobiological bases of rhythmic motor acts in invertebrates. Science 228:143-149.

Grillner S, Georgopoulos AP, Jordan LM (1997) Selection and initiation of motor behavior. In: Neurons, networks, and motor behavior (Stein PSG, Grillner S, Selverston AI, Stuart DG, eds), pp 3-19. Cambridge, MA: MIT.

Harris-Warrick RM, Marder E (1991) Modulation of neuronal network for behavior. Annu Rev Neurosci 14:39-57.

Hawkins R, Clark G, Kandel ER (1985) Operant conditioning and differential classical conditioning of gill withdrawal in Aplysia. Soc Neurosci Abstr 11:796.

Heinzel H-G (1988) Gastric mill activity in the lobster. I. Spontaneous modes of chewing. J Neurophysiol 59:528-550.

Hooper SL, Moulins M (1989) Switching of a neuron from one network to another by sensory-induced changes in membrane properties. Science 244:1587-1589.

Hooper SL, Moulins M, Nonnotte L (1990) Sensory input induces longlasting changes in the output of the lobster pyloric network. J Neurophysiol 64:1555-1573.

Horridge GA (1962) Learning of leg position by headless insects. Nature 193:697-698.

Hoyle G (1979) Mechanisms of simple motor learning. Trends Neurosci 2:153-155.

Hoyle G (1980) Learning, using natural reinforcement, in insect preparations that permit cellular neuronal analysis. J Neurobiol 11:323-354.

Hoyle G (1982) Pacemaker change in a learning paradigm. In: Cellular pacemaker (Carpenter DO, ed), pp 3-25. New York: Wiley.

Hultborn H, Kiehn O (1992) Neuromodulation of vertebrate motor neuron membrane properties. Curr Opin Neurobiol 2:770-775.

Hurwitz I, Susswein AJ (1996) B64, a newly-identified central pattern generator element producing a phase switch from protraction to retraction in buccal motor programs of Aplysia californica. J Neurophysiol 75:1327-1344.

Hurwitz I, Neustadter D, Morton DW, Chiel HJ, Susswein AJ (1996) Activity patterns of the B31/32 pattern initiators innervating the I2 muscle of the buccal mass during normal feeding movements in Aplysia californica. J Neurophysiol 75:1309-1326.

Hurwitz I, Kupfermann I, Susswein AJ (1997) Different roles of neurons B63 and B34 that are active during the protraction phase of the buccal motor programs in Aplysia californica. J Neurophysiol 78:1305-1319.

Jaeger BJ, Olivares SA, Wetzel MC (1987) Operant conditioning in relation to natural EMG during rapid human walking. Am J Phys Med 66:59-76.

Jaffard R, Jeantet Y (1981) Posttraining changes in excitability of the commissural path-CA1 pyramidal cell synapse in the hippocampus of mice. Brain Res 220:167-172.
Jaffard R, Destrade C, Soumireu-Mourat B, Durkin T, Ebel A (1980) Changes in hippocampal cholinergic activity following learning in mice. Neurosci Lett 19:349-352.

Kandel ER, Schwartz JH (1982) Molecular biology of learning: modulation of transmitter release. Science 218:433-443.

Katz PS, Harris-Warrick RM (1991) Recruitment of crab gastric mill neurons into the pyloric motor pattern by mechanosensory afferent stimulation. J Neurophysiol 65:1442-1451.

Kiehn O (1991) Plateau potentials and active integration in the "final common pathway" for motor behavior. Trends Neurosci 14:68-73.

Konorski J (1948) Conditioned reflexes and neuronal organization. Cambridge, UK: Cambridge UP.

Kupfermann I (1974a) Feeding behavior in Aplysia: a simple system for the study of motivation. Behav Biol 10:1-26.

Kupfermann I (1974b) Dissociation of the appetitive and consummatory phases of feeding behavior in Aplysia: a lesion study. Behav Biol 10:89-97.

Lechner HA, Baxter DA, Byrne JH (1997) Classical conditioning of feeding in Aplysia. Soc Neurosci Abstr 23:1334.

Levitan ES, Levitan IB (1988) Serotonin acting via cyclic AMP enhances both the hyperpolarizing and depolarizing phases of bursting pacemaker activity in the Aplysia neuron R15. J Neurosci 8:1152-1161.

Llinas R (1988) The intrinsic electrophysiological properties of mammalian neurons: insights into central nervous system function. Science 242:1654-1664.

Llinas R, Yarom Y (1986) Oscillatory properties of guinea pig inferior olivary neurons and their pharmacological modulation: an in vitro study. J Physiol (Lond) 376:163-182.

Lukowiak K, Ringseis E, Spencer G, Wildering W, Naweed S (1996) Operant conditioning of the aerial respiratory behavior in Lymnaea stagnalis. J Exp Biol 199:683-691.

Lydic R (1989) Central pattern-generating neurons and the search for general principles. FASEB J 3:2457-2468.

Mahajan DS, Desiraju T (1988) Alterations of dendritic branching and spine densities of hippocampal CA3 pyramidal neurons induced by operant conditioning in the phase of brain growth spurt. Exp Neurol 100:1-15.

Maier SF (1989) Learned helplessness: event covariation and cognitive changes. In: Contemporary learning theories (Klein SB, Mowrer RR, eds), pp 73-110. Hillsdale, NJ: LEA.

Marder E, Calabrese RL (1996) Principles of rhythmic motor pattern generation. Physiol Rev 76:687-717.

Marder E, Abbott LF, Turrigiano GG, Liu Z, Golowasch J (1996) Memory from the dynamics of intrinsic membrane currents. Proc Natl Acad Sci USA 93:13481-13486.

McClellan AD (1982) Movements and motor patterns of the buccal mass of Pleurobranchaea during feeding, regurgitation and rejection. J Exp Biol 98:213-228.

Meyrand P, Simmers J, Moulins M (1991) Construction of a patterngenerating circuit with neurons of different networks. Nature 351:60-63.

Meyrand P, Simmers J, Moulins M (1994) Dynamic construction of a neural network from multiple pattern generators in the lobster stomatogastric nervous system. J Neurosci 14:630-644.

Miller NE (1969) Learning of visceral and glandular responses. Science 163:434-445.

Mortin LI, Keifer J, Stein PSG (1985) Three forms of the scratch reflex in the spinal turtle: movement analyses. J Neurophysiol 53:1501-1516.

Morton DW, Chiel HJ (1993a) In vivo buccal nerve activity that distinguishes ingestion from rejection can be used to predict behavioral transitions in Aplysia. J Comp Physiol [A] 172:17-32.

Morton DW, Chiel HJ (1993b) The timing of activity in motor neurons that produce radula movements distinguishes ingestion from rejection in Aplysia. J Comp Physiol [A] 173:519-536.

Nargeot R, Moulins M (1997) Sensory-induced plasticity of motor pattern selection in the lobster stomatogastric nervous system. Eur J Neurosci 9:1636-1645.

Nargeot R, Baxter DA, Byrne JH (1997a) Dynamic recruitment of neurons into the central pattern generator (CPG) for feeding is associated with motor pattern selection in Aplysia. Soc Neurosci Abstr 23:1046.

Nargeot R, Baxter DA, Byrne JH (1997b) Contingent-dependent enhancement of rhythmic motor patterns: an in vitro analog of operant conditioning. J Neurosci 17:8093-8105.

Nargeot R, Baxter DA, Byrne JH (1998) Contingent reinforcement in an analogue of operant conditioning modified the intrinsic membrane 
properties of an identified Aplysia neuron (B51). Soc Neurosci Abstr 24:1890.

Nargeot R, Baxter DA, Byrne JH (1999a) In vitro analog of operant conditioning in Aplysia. II. Modifications of the functional dynamics of an identified neuron contribute to motor pattern selection. J Neurosci 19:2261-2272.

Nargeot R, Baxter DA, Patterson GW, Byrne JH (1999b) Dopaminergic synapses mediate neuronal changes in an analogue of operant conditioning. J Neurophysiol, in press.

Pearson KG (1993) Common principles of motor control in vertebrates and invertebrates. Annu Rev Neurosci 16:265-297.

Plummer MR, Kirk MD (1990) Premotor neurons B51 and B52 in the buccal ganglia of Aplysia californica: synaptic connections, effect on ongoing motor rhythms, and peptide modulation. J Neurophysiol 63:539-558.

Rossignol S, Dubuc R (1994) Spinal pattern generation. Curr Opin Neurobiol 4:894-902.

Russell DF, Hartline DK (1978) Bursting neural networks: a reexamination. Science 200:453-456.

Russo RE, Hounsgaard J (1996) Plateau generating neurones in the dorsal horn in an in vitro preparation of the turtle spinal cord. J Physiol (Lond) 493:39-54.

Schulz H (1987) One-trial instrumental conditioning in rats. Acta Physiol Hung 70:111-115.

Selverston AI, Moulins M (1985) Oscillatory neural networks. Annu Rev Physiol 47:29-48.

Skelton W, Scarth AS, Wilkie DM, Miller JJ, Phillips AG (1987) Longterm increases in dentate granule cell responsivity accompany operant conditioning. J Neurosci 7:3081-3087.

Skinner BF (1938) The behavior of organisms: an experimental analysis. New York: Appleton-Century-Crofts.

Skinner BF (1966) The phylogeny and ontogeny of behavior: contingencies of reinforcement throw light on contingencies of survival in the evolution of behavior. Science 153:1205-1213.
Skinner BF (1981) Selection by consequences. Science 213:501-504.

Spencer G, Inoue I, Cotter R, Syed N, Lukowiak K (1996) Alterations in synaptic activity to and within a CPG may underlie the operant conditioning of aerial respiratory behaviour in Lymnaea. Soc Neurosci Abstr 22:1404.

Susswein AJ, Byrne JH (1988) Identification and characterization of neurons initiating patterned neural activity in the buccal ganglia of Aplysia. J Neurosci 8:2049-2061.

Susswein AJ, Schwarz M, Feldman E (1986) Learned changes of feeding behavior in Aplysia in response to edible and inedible foods. J Neurosci 6:1513-1527.

Thompson RF (1988) The neuronal basis of basic associative learning of discrete behavioral responses. Trends Neurosci 11:152-155.

Thorndike EL (1911) Animal intelligence: experimental studies. New York: Macmillan.

Thorndike EL (1933) A proof of the law of effect. Science 77:173-175.

Turrigiano G, Abbott LF, Marder E (1994) Activity-dependent changes in the intrinsic properties of cultured neurons. Science 264:974-977.

Walters ET, Byrne JH, Carew TJ, Kandel ER (1983) Mechanoafferent neurons innervating tail of Aplysia. II. Modulation by sensitizing stimulation. J Neurophysiol 50:1543-1559.

Weimann JM, Marder E (1994) Switching neurons are integral members of multiple oscillatory networks. Curr Biol 4:896-902.

Wolpaw JR (1987) Operant conditioning of primate spinal reflexes: the H-reflex. J Neurophysiol 57:443-459.

Wolpaw JR (1997) The complex structure of a simple memory. Trends Neurosci 20:588-594.

Woollacott M, Hoyle G (1977) Neural events underlying learning in insects: changes in pacemaker. Proc $\mathrm{R}$ Soc Lond B Biol Sci 195:395-415.

Zar JH (1996) Biostatistical analysis, Ed 3. Englewood Cliffs, NJ: Prentice-Hall. 